\title{
Die Altersversorgung von Beamten in der Russischen Föderation
}

\author{
Olga Chesalina
}

I. Grundlegung

1. System des Staatsdienstes in der Russischen Föderation

2. Bestehen eines „Berufsbeamtentums“ und Grundsätze der Beamtenverhältnisse

a) Historische Entwicklung des russischen Staatsdienstes

b) Verfassungsrechtliche und einfachgesetzliche Regelungen für die hoheitliche Aufgaben wahrnehmenden Staatsbediensteten

c) Verfassungsrechtliche und einfachgesetzliche Grundsätze des Staatsdienstes

3. Status der zivilen Staatsbediensteten und Kommunalbediensteten

a) Status der zivilen Staatsbediensteten

b) Status der Kommunalbediensteten

c) Verfassungsrechtliche Zulässigkeit der Statusregelungen

4. Erfordernis einer besonderen sozialen Sicherung der Beamten im Alter aufgrund der Besonderheiten der Stellung der Staatsbediensteten

II. Ausgestaltung der Altersabsicherung von Staatsbediensteten

1. Grundlegende Unterschiede zwischen den Alterssicherungssystemen für zivile Staatsbedienstete und Kommunalbedienstete und dem allgemeinen Alterssicherungssystem für Arbeitnehmer

a) Allgemeines System der Alterssicherung für Arbeitnehmer

b) Alterssicherung der zivilen Staatsbediensteten

c) Staatsbedienstete der Subjekte der Föderation und Kommunalbedienstete

2. Voraussetzungen des Erhalts einer Alterspension für zivile Staatsbedienstete

3. Leistungsbemessung der Alterspension für zivile Staatsbedienstete

4. Anpassungen der Alterspension für zivile Staatsbedienstete

5. Finanzierung der Alterssicherung der Staatsbediensteten

III. Auswertung 


\section{Grundlegung}

\section{System des Staatsdienstes in der Russischen Föderation}

Die Grundlagen des Staatsdienstes der Russischen Föderation (RF) und der ihr angeschlossenen Republiken, Gebiete und Bezirke (Subjekte der RF) i.S.d. Art. 65 Teil 1 der Verfassung der Russischen Föderation ${ }^{1}$ (Verf RF) sind im Föderationsgesetz Nr. 58 vom 27. Mai 2003 „Über das System des Staatsdienstes der Russischen Föderation“2 (SDSG) geregelt.

Der „Staatsdienst“ umfaßt gemäß Art. 1 Teil 1 SDSG ,die professionelle dienstliche Tätigkeit der Bürger der RF zur Erfüllung der Zuständigkeiten

- der RF;

- der föderalen Organe der Staatsgewalt, anderer föderaler staatlicher Organe;

- der Subjekte der RF;

- der Organe der Staatsgewalt der Subjekte der RF, anderer staatlicher Organe der Subjekte der RF;

- der Personen, die Ämter wahrnehmen, die gemäß der Verf RF und den Föderationsgesetzen unmittelbarer Teil der föderalen Staatsgewalt sind;

- der Personen, die Ämter wahrnehmen, die gemäß den Verfassungen, Statuten und Gesetzen der Subjekte der RF unmittelbarer Teil der Staatsgewalt der Subjekte der RF sind."

Für die beiden letztgenannten Personengruppen („Staatsämter“, z.B. Minister, aber auch Richter $)^{3}$ findet das SDSG allerdings gemäß seinem Art. 1 Teil 2 keine Anwendung. ${ }^{4}$ Der ,Staatsdienst“ ist weiter abzugrenzen von Tätigkeiten, die zwar für staatliche Organe erbracht werden, die aber nicht zu den „Ämtern des Staatsdienstes“5 i.S.d.

1 Die Verfassung der RF wurde durch Volksabstimmung vom 12. Dezember 1993 angenommen. Sie wurde 1994 in Nr. 4 der Gesetzessammlung der RF (SZRF) unter Art. 445 verkündet und wurde zuletzt geändert durch das Föderale Verfassungsgesetz Nr. 7 vom 30. Dezember 2008 (SZRF 2009 Nr. 1 Art. 2).

2 SZRF Nr. 22 Art. 2063, zuletzt geändert durch Föderationsgesetz Nr. 309 vom 1. Dezember 2007 (SZRF Nr. 49 Art. 6070).

3 Im Einzelnen zählen zu den „Staatsämtern“ die im Erlaß Nr. 32 des Präsidenten der RF vom 11. Januar 1995 (SZRF Nr. 3 Art. 173), zuletzt geändert durch Erlaß Nr. 1658 vom 1. Dezember 2008 (SZRF Nr. 49 Art. 5763), bezeichneten Ämter.

4 Ovsyanko, Gosudarstvennaya sluzhba Rossiyskoy Federatsii (Der Staatsdienst der Russischen Föderation), 3. Aufl. 2006, S. 47.

5 Im Einzelnen zählen gemäß Art. 8 SDSG zu den „Ämtern des Staatsdienstes“ die durch Föderationsgesetz oder andere normative Akte der Russischen Föderation und der Subjekte der Föderation für die jeweiligen Arten des Staatdienstes festgelegten Ämter. Vgl. insoweit für den zivilen Staatsdienst den Erlaß des Präsidenten der RF Nr. 1574 vom 31. Dezember 2005 „Über das Register der staatlichen Ämter der föderalen Staatsbediensteten“ (SZRF 2006 Nr. 1 Art. 118), zuletzt geändert durch Erlaß Nr. 544 vom 13. Mai 2009 (SZRF 2009 Nr. 20 Art. 2445). 
SDSG zählen und deren Aufnahme, Ausübung und Beendigung ausschließlich dem Arbeitsrecht unterliegt (zu diesem Personenkreis zählt i.d.R. nur Hilfspersonal, z.B. Wachdienst). ${ }^{6}$

Der Staatsdienst unterteilt sich gemäß Art. 2 Teil 1 SDSG in den „Zivilen Staatsdienst“, den „Militärdienst““ und den „Rechtsschutzdienst““.7 Gemäß Art. 10 Teil 1 SDSG ist „föderaler Staatsbediensteter“, wer eine professionelle dienstliche Tätigkeit im Rahmen eines Amtes des föderalen „Staatsdienstes“ ausübt und Bezüge aus Haushaltsmitteln der RF erhält. ${ }^{8}$

$\mathrm{Zu}$ beachten ist, daß die Organe der kommunalen Selbstverwaltung gemäß Art. 12 Satz 3 Verf RF nicht ,zum System der Organe der Staatsgewalt“ gehören. Entsprechend wird der „Kommunaldienst“ nicht zum Staatsdienst gerechnet. ${ }^{9}$ In der Literatur wird aber betont, daß Staatsdienst und Kommunaldienst zwei sehr ähnliche und wechselseitig zusammenhängende Arten des „öffentlichen Dienstes“ darstellen. 10

\section{Bestehen eines „Berufsbeamtentums“ und Grundsätze der Beamtenverhältnisse}

\section{a) Historische Entwicklung des russischen Staatsdienstes}

Das Berufsbeamtentum wurde in Russland nach der Revolution durch Dekret des Zentralexekutivkomitees vom 10. November $1917^{11}$ abgeschafft. In sowjetischen

6 Ovsyanko, Gosudarstvennaya sluzhba Rossiyskoy Federatsii (Fußn. 4), S. 48.

7 Der zivile Staatsdienst ist dabei gemäß Art. 2 Teil 2 SDSG zwischen der RF und ihren Subjekten aufgeteilt, wohingegen es sich bei Militär- und Rechtsschutzdienst gemäß Art. 2 Teil 3 SDSG ausschließlich um föderalen Staatsdienst handelt. Die Besonderheiten des Militär- und Rechtsschutzdienstes werden in diesem Beitrag nicht behandelt. Der Status der Militär- und Rechtsschutzbediensteten und ihre Altersversorgung ist rein öffentlich-rechtlich geregelt (vgl. auch Fußn. 91).

8 Eine entsprechend lautende Definition enthält Art. 10 Teil 2 SDSG für den Begriff des „Staatsbediensteten eines Subjekts der Russischen Föderation“ (dienstliche Tätigkeit im „Staatsdienst“ des Subjekts der RF, vergütet aus Haushaltsmitteln des Subjekts der RF).

9 Art. 6 des Föderationsgesetzes Nr. 25 vom 2. März 2007 „Über den Kommunaldienst in der Russischen Föderation“ (SZRF Nr. 10 Art. 1152, zuletzt geändert durch Föderationsgesetz Nr. 280 vom 25. Dezember 2008, SZRF Nr. 52 Art. 6235) definiert das „Amt des Kommunalbediensteten“ als Amt in einem Organ der örtlichen Selbstverwaltung, das entsprechend einem kommunalen Statut zur Erfüllung der Zuständigkeiten des Organs der örtlichen Selbstverwaltung vorgesehen ist; mit Entscheidungen Nr. 19-P vom 15. Dezember 2003, Nr. 60-O vom 10. April 1997 und Nr. 23-O vom 14. Januar 1999 hat das Verfassungsgericht der RF (VerfG RF) bestätigt, daß der Gesetzgeber in Anbetracht der ähnlichen Situation wie bei den Staatsbediensteten auch hinsichtlich der Kommunalbediensteten berechtigt ist, ihre Dienstverhältnisse einem besonderen rechtlichen Regime zu unterstellen.

10 Obolonskiy, Gosudarstvennaya sluzhba: kompleksnyy podkhod (Der Staatsdienst - eine übergreifende Betrachtung), 2009, S. 133.

11 Dekret des Zentralexekutivkomitees der Russischen Sozialistischen Föderativen Sowjetrepublik (RSFSR) vom 10. Oktober 1917 „Über die Abschaffung aller Stände und zivilen Ränge“, SZ 
Rechtsakten wurde seit den 1920er Jahren der Terminus „Staatsdienst“ verwendet. Obwohl die Staatsbediensteten in der Sowjetunion als einfache „Werktätige“ angesehen wurden, die auf Grundlage gewöhnlicher Arbeitsverträge tätig waren, bildeten sie schon bald eine privilegierte Schicht. ${ }^{12}$ Ihre berufliche Existenz und ihr Fortkommen waren abhängig von ihrer Ergebenheit gegenüber der Kommunistischen Partei und den unmittelbaren Vorgesetzten. ${ }^{13}$ Eine Regelung von Grundsätzen des Staatdienstes und der Rechtstellung der Staatsbediensteten existierte bis zum Ende der Sowjetunion nicht. ${ }^{14}$

Erst 1991, im Jahr des Zusammenbruchs der Sowjetunion, begann eine Reform des russischen Staatsdienstrechts. Wesentliche Ziele waren die politische Neutralität des Staatsdienstes, seine Verpflichtung auf die Achtung der Menschenrechte und die Steigerung seiner Leistungsfähigkeit und Stabilität. Erst seitdem lässt sich in Russland wieder von einem professionellen Staatsdienst sprechen, für den teilweise in der Literatur auch der Begriff des „Berufsbeamtentums“ gebraucht wird. 15

b) Verfassungsrechtliche und einfachgesetzliche Regelungen für die hoheitliche Aufgaben wahrnehmenden Staatsbediensteten

Die am 12. Dezember 1993 in Kraft getretene Verf RF verwendet für Staatsbedienstete, denen die Wahrnehmung hoheitlicher Aufgaben anvertraut ist, den Begriff der „Amtsperson“ (,,dolžnostnoe lico“). ${ }^{16}$ Dieser Begriff wurde bereits seit den 1860er Jahren in amtlichen Dokumenten an Stelle des bis dahin gebrauchten und bis heute umgangssprachlich üblichen Begriffs „Beamter“ (,činovnik“17) verwendet. 18

Bezüglich der Amtspersonen enthält die VerfRF folgende Bestimmungen:

- Im Zusammenhang mit der Regelung der Verwaltungskompetenzen bestimmt Art. 78 Teil 1 Verf RF, daß die föderalen Organe der vollziehenden Gewalt zur Ausübung ihrer Befugnisse eigene territoriale Organe bilden und entsprechende Amtspersonen ernennen können.

RSFSR 1917 Nr. 3 Art. 31; vgl. auch Fritzsche, Der zivile Staatsdienst in der Russischen Föderation, 2006, S. 83.

12 Starilov, Neuere Reformansätze im russischen Dienstrecht - Rußland auf dem Weg zum Berufsbeamtentum, 1994, S. 36 ff. und 109.

13 Fritzsche, Der zivile Staatsdienst in der Russischen Föderation (Fußn. 11), S. 117.

14 Fritzsche, Der zivile Staatsdienst in der Russischen Föderation (Fußn. 11), S. 94.

15 Starilov, Neuere Reformansätze im russischen Dienstrecht (Fußn. 12), S. 108, 112 und 121.

16 Fritzsche, Der zivile Staatsdienst in der Russischen Föderation (Fußn. 11), S. 259.

17 Der Begriff stammt von dem Wort „čin“ („,Rang“) und bedeutet, daß eine Person einen bestimmten Rang einer Ämterlaufbahn einnimmt, d.h. Beamter ist. Der Terminus „čin“ bzw. „klassny čin“ („Rangklasse“) wird auch vom SDSG in Art. 13 verwendet, der bestimmt, daß für den „Staatsdienst“ in den Föderationsgesetzen „Rangklassen“, diplomatische Ränge und Militär- und Sonderränge zu regeln sind.

18 Starilov, Neuere Reformansätze im russischen Dienstrecht (Fußn. 12), S. 32 und 62. 
- Gemäß Art. 15 Teil 2 Verf RF sind die Organe der Staatsgewalt, die Organe der örtlichen Selbstverwaltung, die Amtpersonen, Bürger und ihre Vereinigungen verpflichtet, die Verf RF und die Gesetze zu beachten.

- Im Zusammenhang mit der Regelung des Grundrechts auf Datenschutz bestimmt Art. 24 Teil 2 Verf RF, daß die Organe der Staatsgewalt und die Organe der örtlichen Selbstverwaltung sowie ihre Amtspersonen verpflichtet sind, jedem die Möglichkeit zur Einsicht in Dokumente und Materialien zu gewähren, die unmittelbar seine Rechte und Freiheiten berühren, soweit nicht gesetzlich etwas anderes bestimmt ist.

- Im Zusammenhang mit der Regelung des Grundrechts auf Rechtsschutz (Art. 46 Verf RF) bestimmt Art. 46 Teil 2 Verf RF, daß gegen Entscheidungen und Handlungen (oder Unterlassen) der Organe der Staatsgewalt, der Organe der örtlichen Selbstverwaltung, der öffentlichen Körperschaften und von Amtspersonen der Rechtsweg offensteht.

- Weiter bestimmt Art. 53 Verf RF, daß jeder das Recht auf staatlichen Ersatz des Schadens, der durch ungesetzliches Handeln (oder Unterlassen) der Organe der Staatsgewalt oder ihrer Amtspersonen verursacht wurde, hat. Art. 41 Teil 3 Verf RF regelt zudem die Haftung von Amtspersonen, die Tatsachen und Umstände verheimlichen, die eine Gefahr für Leben und Gesundheit von Menschen darstellen. 19

Einfachgesetzlich zeichnet sich die Rechtstellung der Amtspersonen durch eine besondere straf- und ordnungswidrigkeitsrechtliche Verantwortlichkeit aus. Insbesondere findet sich in Teil 1 der Anmerkung zu Art. 285 Strafgesetzbuch RF 20 (StGB RF) eine Definition des Begriffs der Amtsperson. Danach sind Amtspersonen i.S.d. vorliegenden Kapitels „Personen, die dauerhaft, befristet oder aufgrund besonderer Ermächtigung Funktionen eines Vertreters der Staatsgewalt wahrnehmen oder organisatorischverfügende, verwaltungswirtschaftliche Funktionen in Behörden, Organen der örtlichen Selbstverwaltung, staatlichen und kommunalen Einrichtungen und bei den Streitkräften der RF ausüben." 21 Eine ähnlich lautende Definition enthält die Anmerkung zu Art. 2.4 Ordnungswidrigkeitsgesetz RF ${ }^{22}$. Art. 285 StGB RF bestimmt, daß Staatbedienstete und Bedienstete der Organe der kommunalen Selbstverwaltung, „die keine Amtsperso-

19 Entsprechende Formulierung in Art. 53 des Föderationsgesetzes Nr. 30 „Über das sanitärepidemiologische Wohlergehen der Bevölkerung“ vom 30. März 1999 (SZRF Nr. 14 Art. 1650), zuletzt geändert durch Föderationsgesetz Nr. 309 vom 30. Dezember 2008 (SZRF Nr. 1 Art. 17).

20 Föderationsgesetz Nr. 63 vom 13. Juni 1996 (SZRF Nr. 25 Art. 2954), zuletzt geändert durch Föderationsgesetz Nr. 141 vom 29. Juni 2009 (SZRF Nr. 26 Art. 3139).

21 Übersetzung in Anlehnung an Fritzsche, Der zivile Staatsdienst in der Russischen Föderation (Fußn. 11), S. 461.

22 Föderationsgesetz Nr. 195 vom 30. Dezember 2001 „Über Ordnungswidrigkeiten“ (SZRF 2002 Nr. 1 Art. 1), zuletzt geändert durch Föderationsgesetz Nr. 209 vom 24. Juli 2009 (SZRF Nr. 30 Art. 3735). 
nen sind", strafrechtlich nur dann haften, wenn dies speziell in Kapitel 30 StGB RF23 bestimmt ist.

Eine zusammenfassende Regelung von besonderen Grundsätzen für Amtspersonen bzw. die Beamtenschaft oder des Status bzw. der Rechte und Pflichten von Amtspersonen bzw. Beamten enthält weder die Verf RF noch das einfache Recht der RF. Die insoweit für den Staatsdienst erlaßenen Grundsatzregelungen ${ }^{24}$ beziehen sich auf den Staatsdienst insgesamt, d.h. ohne Unterschied auch auf diejenigen Staatsbediensteten, die nicht mit der Wahrnehmung hoheitlicher Aufgaben betraut sind. ${ }^{25}$

\section{c) Verfassungsrechtliche und einfachgesetzliche Grundsätze des Staatsdienstes}

Die Verf RF enthält für den „Staatsdienst“ in Art. 32 Teil 4 Verf RF die Bestimmung, daß die Bürger der RF gleichen Zugang zum Staatsdienst haben. ${ }^{26}$ In der Literatur wird hierzu ausgeführt, daß hierdurch allen Bürger ohne Diskriminierung ein Recht auf Beschäftigung im Rahmen eines beliebigen „öffentlichen Amts“ entsprechend ihren Fähigkeiten und ihrer beruflichen Ausbildung gewährt wird. ${ }^{27}$ VerfG RF betont die Bedeutung von Art. 32 Teil 4 Verf RF als Ausprägung des Demokratieprinzips (Art. 1 Teil 1 Verf RF, Art. 3 Verf RF), indem es das Institut der Wettbewerbsauslese für die Besetzung der „„̈ffentlichen Ämter“ als die „demokratische Garantie“ des Verfassungsrechts auf Zugang zum Staatsdienst bezeichnet. ${ }^{28}$

23 Das Kapitel 30 (Art. 285 ff.) des StGB RF trägt die Überschrift „Verbrechen gegen die Staatsgewalt, die Interessen des Staatsdienstes und des Dienstes in Organen der örtlichen Selbstverwaltung“.

24 SDSG und Gesetze für die einzelnen Arten des Staatsdienstes.

25 Vgl. auch Fritzsche, Der zivile Staatsdienst in der Russischen Föderation (Fußn. 11), S. 163, die darauf hinweist, daß es ,keine Unterteilung der einzelnen Staatsbediensteten in Beamte, die einem öffentlich-rechtlichen Hoheitsverhältnis unterstehen, und Angestellten, auf die sich das Arbeitsrecht erstreckt“", gibt. Zur Rechtsnatur der „Dienstverhältnisse“ vgl. unten unter I. 3. a).

26 Diese Regelung setzt Art. 25 des Internationalen Paktes über bürgerlichen und politischen Rechte um, vgl. Lazarev, Online-Kommentariy k Konstitutsii Rossiyskoy Federatsii (Onlinekommentar zur Verfassung der Russischen Föderation) zum Stand vom 1. Mai 2003 (unter: http://www.constitution.garant.ru/DOC_3848902.htm). Das Recht auf Zugang zum Kommunaldienst ist in der Verf RF nicht ausdrücklich geregelt, folgt jedoch aus Art. 3 Teil 2, Art. 12 und Art. 130 Verf RF, vgl. Kireyeva, Subyekty prava na ravnyy dostup k gosudarstvennoy i munitsipal'noy sluzhbe (Die subjektiven Rechte auf gleichen Zugang zum Staats- und Kommunaldienst), Konstitutsionnoye i munitsipal'noye pravo 2/2009, S. 10.

27 Okun'kov, Online-Kommentariy k Konstitutsii Rossiyskoy Federatsii, Institut zakonodatel'stva i sravnitel'nogo pravovedeniya pri Pravitel'stve Rossiyskoy Federatsii (Onlinekommentar zur Verfassung der Russischen Föderation des Instituts für Gesetzgebung und Rechtsvergleichung bei der Regierung der Russischen Föderation) (unter: http://www.constitution.garant.ru/DOC_3301000.htm).

28 Entscheidung Nr. 2-P des VerfG RF vom 3. Februar 2009. Art. 22 ZDG setzt dies dahingehend um, daß Stellenbesetzungen ,in der Regel“ durch Wettbewerb im Rahmen einer Stellenausschreibung erfolgen. Auswahlkriterien sind gemäß Art. 22 Punkt 1 Satz 2 ZDG das professionelle Niveau der Bewerber im Hinblick auf die zu besetzende Stelle und die Erfüllung der Eignungskriterien für den zivilen Staatsdienst. Auf eine Ausschreibung kann jedoch in vielen Fällen, wie den in Art. 22 Punkt 2 bis 4 ZDG aufgezählten, verzichtet werden (z.B. bei befristeter Einstellung). 
Weiter bestimmt Art. 71 Buchst. t Verf RF im Zusammenhang mit den Gesetzgebungskompetenzen, daß zu den Zuständigkeiten der Föderation der föderale Staatsdienst gehört. Dagegen kennt die Verf RF keine Sicherung von „hergebrachten Grundsätzen“, wie sie Art. 33 Abs. 5 GG für das Berufsbeamtentum vorsieht. Zum einen bestanden auf Grund der Sowjetzeit keine entsprechenden Traditionen, an die in Form einer solchen Generalklausel angeknüpft hätte werden können. ${ }^{29}$ Zum anderen musste der Staatsdienst des demokratischen Russland gerade im Gegensatz zur sowjetischen Verwaltung konzipiert werden, die parteipolitisch abhängig, von persönlichen Beziehungen geprägt, mit Privilegien ausgestattet und bürokratisch bzw. ineffizient war. ${ }^{30}$

An Stelle einer Generalklausel mit Verfassungsrang sind in der RF die Prinzipien des Staatsdienstes einfachgesetzlich und sehr detailliert geregelt. Erstmals geschah dies in zusammenhängender Form durch das am 31. Januar 2005 außer Kraft getretene Föderationsgesetz Nr. 119 vom 31. Juli 1995 „Über die Grundlagen des Staatsdienstes der Russischen Föderation“31 (Staatdienstgrundlagengesetz 1995). Heute sind die Prinzipien des Staatdienstes in Art. 3 SDSG geregelt, der ergänzt wird durch die Normierung von Prinzipien in den Gesetzen über die einzelnen Arten des Staatsdienstes. Für den zivilen Staatsdienst treffen Art. 4 und 7 des Föderationsgesetzes Nr. 79 vom 27. Juli 2004 „Über den zivilen Staatsdienst der RF“32 (ZDG) die entsprechenden Regelungen. ${ }^{33}$ Die in diesen Bestimmungen enthaltenen Grundsätze werden in der Literatur unterteilt in Prinzipien, die verfassungsrechtliche Bindungen der Verwaltung wiederholen und teilweise konkretisieren (verfassungsrechtliche Prinzipien) und organisatorische Prinzipien. ${ }^{34}$ Im Gesetzeswortlaut kommt diese Unterscheidung allerdings nicht zum Ausdruck. Die meisten der geregelten Prinzipien haben ganz oder zumindest teilweise einen verfassungsrechtlichen Hintergrund ${ }^{35}$ :

- Gesetzmäßigkeit (Art. 3 Teil 1 Abs. 2 SDSG) - dieses Prinzip nimmt Bezug auf den Grundsatz der Gesetzmäßigkeit der Verwaltung nach Art. 15 Teil 2 Verf RF.

- Priorität der Rechte und Freiheiten des Menschen und Bürgers, insbesondere die Verpflichtung des Staatsdienstes zur ihrer Anerkennung, Beachtung und ihrem

29 Fritzsche, Der zivile Staatsdienst in der Russischen Föderation (Fußn. 11), S. 214.

30 Starilov, Neuere Reformansätze im russischen Dienstrecht (Fußn. 12), S. 14, 109, 121.

31 SZRF 1995 Nr. 31 Art. 2290, zuletzt geändert durch das SDSG, aufgehoben zum Inkrafttreten des ZDG, vgl. Art. 72 Nr. 1 i.V.m. Art. 71 Punkt 1 ZDG.

32 SZRF Nr. 31 Art. 3215, zuletzt geändert durch Föderationsgesetz Nr. 187 vom 18. Juli 2009 (SZRF Nr. 29 Art. 3624). Das ZDG hat mit seinem Inkrafttreten am 1. Februar 2005 das Staatdienstgrundlagengesetz 1995 abgelöst, vgl. Art. 72 Nr. 1 i.V.m. Art. 71 Punkt 1 ZDG.

33 Das SDSG und das ZDG sind das Ergebnis der ersten großen Reform des Staatsbedienstetenrechts in der RF. Die wesentlichen Reformziele waren im Erlaß Nr. 136 des Präsidenten der RF vom 19. November 2002 „Über das föderale Programm: Die Reform des Staatsdienstes der Russischen Föderation (2003-2005)“ (SZRF Nr. 47 Art. 4664), zuletzt geändert durch Erlaß des Präsidenten der RF Nr. 1437 vom 12. Dezember 2005 (SZRF Nr. 51 Art. 5514), formuliert worden. Als Ziel der Reform nennt der Erlaß die Erhöhung der Effektivität des Staatsdienstes.

34 Fritzsche, Der zivile Staatsdienst in der Russischen Föderation (Fußn. 11), S. 213.

35 Obolonskiy, Gosudarstvennaya sluzhba: kompleksnyy podkhod (Fußn. 10), S. 61. 
Schutz (Art. 3 Teil 1 Abs. 3 SDSG, Art. 4 Punkt 2 ZDG) - dieses Prinzip entspricht Art. 2 und Art. 18 VerfRF, wonach der Mensch, seine Rechte und Freiheiten die höchsten Werte sind, diese unmittelbar gelten und deren Anerkennung, Achtung sowie Schutz die Pflicht des Staates ist. ${ }^{36}$

- Transparenz des Staatsdienstes und seine Zugänglichkeit für eine öffentliche Kontrolle (Art. 3 Teil 1 Abs. 7 SDSG, Art. 4 Punkt 6 ZDG) - dies ist Ausdruck des Demokratieprinzips (Art. 1 Teil 1, Art. 3 Verf RF).

- Gleicher Zugang der Bürger zum Staatsdienst (Art. 3 Teil 1 Abs. 4 SDSG, Art. 4 Punkt 3 ZDG) - dieses Prinzip entspricht Art. 32 Teil 4 Verf RF.

- Stabilität des zivilen Staatsdienstes (Art. 4 Punkt 5 ZDG) - dieses Prinzip soll dem Staatsdienst Widerstandsfähigkeit gegenüber und Unabhängigkeit von politischen Veränderungen verleihen. ${ }^{37}$ Da seit Außerkrafttreten des Staatsdienstgrundlagengesetzes 1995 zum 31. Januar 2005 keine explizite Regelung der Überparteilichkeit der Beamtenschaft ${ }^{38}$ mehr existiert, wird im Stabilitätsprinzip in der Literatur die Verankerung der Neutralität des Staatdienstes gesehen. ${ }^{39}$

- Der Föderalismus, „der die Einheit des Systems des Staatsdienstes und die Beachtung der verfassungsrechtlichen Abgrenzung der Kompetenzen und Befugnisse zwischen föderalen Organen der Staatsgewalt sowie den Organen der Staatsgewalt der Subjekte der RF gewährleistet" (Art. 3 Teil 1 Abs. 1 SDSG) - diese Bestimmung nimmt auf Art. 5 Teil 3 Verf RF Bezug, wonach sich der Föderalismus der RF auf die Einheit des Systems der Staatsgewalt und auf die Abgrenzung der Kompetenzen und Befugnisse zwischen den Organen der Staatsgewalt der RF und der Subjekte der Föderation gründet. 40

- Einheitlichkeit ${ }^{41}$ der rechtlichen und organisatorischen Grundlagen des Staatsdienstes der Föderation und der Subjekte der Föderation (Art. 3 Teil 1 Abs. 5 SDSG Art. 4 Punkt 2 ZDG). 42

- Wechselbeziehungen zwischen Staatsdienst und Kommunaldienst (Art. 3 Teil 1 Abs. 6 SDSG, Art. 7 ZDG).

36 Obolonskiy, Gosudarstvennaya sluzhba: kompleksnyy podkhod (Fußn. 10), S. 66.

37 Fritzsche, Der zivile Staatsdienst in der Russischen Föderation (Fußn. 11), S. 246.

38 Vgl. Art. 5 Nr. 11 Staatsdienstgrundlagengesetz 1995.

39 Fritzsche, Der zivile Staatsdienst in der Russischen Föderation (Fußn. 11), S. 246.

40 Obolonskiy, Gosudarstvennaya sluzhba: kompleksnyy podkhod (Fußn. 10), S. 72. Als Grundlage der Einheit des Systems der Staatsgewalt wird zudem teilweise Art. 3 Teil 1 Verf RF (,alleinige Quelle der Staatsgewalt ist das multinationale Volk der Russischen Föderation") angeführt und daraus das Erfordernis einer gleichförmigen Regulierung von Grundlagen des Staatsdienstes aller staatlichen Ebenen abgeleitet, Fritzsche, Der zivile Staatsdienst in der Russischen Föderation (Fußn. 11), S. 226.

41 Fomina, Yedinstvo sistemy gosudarstvennoy sluzhby i yego vliyaniye na pravovoye regulirovaniye pensionnogo obespecheniya gosudarstvennykh sluzhashchikh (Die Einheit des Systems des Staatsdienstes und ihr Einfluss auf die rechtliche Regelung der Pensionsversorgung der Staatsbediensteten), LEX RUSSICA/ Nauchnyye trudy MGYUA 2007 Nr. 2 S. 409, 410.

42 Ovsyanko, Gosudarstvennaya sluzhba Rossiyskoy Federatsii (Fußn. 4), S. 44. 
Der letztgenannte Grundsatz bedeutet, daß für zivilen Staatsdienst und Kommunaldienst ähnliche Strukturen vorzusehen sind. ${ }^{43}$ Art. 7 ZDG und Art. 5 KDG (KDG) enthalten hierzu folgende Vorgaben:

- Einheitlichkeit der grundlegenden Qualifikationsforderungen,

- Einheitlichkeit der Anforderungen an Aus- und Fortbildung,

- Einheitlichkeit der persönlichen Beschränkungen und Verpflichtungen, ${ }^{44}$

- Einheitliche Berechnung des Dienstalters und Anrechnung der Dienstzeiten im Fall des Wechsels zwischen Staatsdienst und Kommunaldienst, ${ }^{45}$

- Vergleichbarkeit der Besoldungsgrundlagen und der sozialen Garantien,

- Vergleichbarkeit der Pensions- und Hinterbliebenenversorgung.

Keine Erwähnung in der Einzelnormierung der Grundsätze des Staatsdienstes findet in der Verf RF und den einschlägigen Gesetzen eine besondere (öffentlich-rechtlich geprägte) Treuepflicht der Staatsbediensteten. Ein weiterer wesentlicher Unterschied zu den „hergebrachten Grundsätzen“ des Art. 33 Abs. 5 GG ist zudem das Fehlen des Lebenszeitprinzips und des Alimentationsprinzips. Das Fehlen derartiger Prinzipien ist Ausdruck dessen, daß die Dienstverhältnisse der Staatsbediensteten auch arbeitsrechtlichen Charakter haben.

\section{Status der zivilen Staatsbediensteten und Kommunalbediensteten}

\section{a) Status der zivilen Staatsbediensteten}

In der RF ist zumindest einfachgesetzlich festgelegt, daß wegen der besonderen Art der wahrzunehmenden Aufgaben die Ausgestaltung ihrer Tätigkeit besonderen (öffentlich-rechtlichen) Grundsätzen unterliegt. Zum „Status der Staatsbediensteten“ bestimmt Art. 10 Teil 4 SDSG, daß sich deren Rechtsstellung, insbesondere die sich aus diesem Verhältnis zum Staat ergebenden Einschränkungen, Verpflichtungen, Regelungen des dienstlichen Verhaltens, Verantwortlichkeiten sowie die besonderen Regelungen für Interessenkonflikte und Beilegung dienstlicher Streitigkeiten nach dem für den jeweiligen Bereich des Staatsdienstes geltendem Föderationsgesetz richtet.

Für die „zivilen Staatsbediensteten“ enthält das ZDG in seinem Kapitel 3 (Art. 13 ff.) die Regelungen zum Status. Kennzeichen des Status der zivilen Staatsbediensteten sind zum einen bestimmte Beschränkungen und Verbote, z.B. im Bereich von Nebentätigkeiten, zum anderen bestimmte rechtliche und soziale Garantien. Die Garantien sind für die zivilen Staatsbediensteten in Art. 14 ZDG genannt und in Art. 52 ZDG näher ausgestal-

43 Ovsyanko, a.a.O.

44 Die Beschränkungen, die mit dem zivilen Staatsdienst verbunden sind, sind identisch mit den Beschränkungen, die mit dem Kommunaldienst verbunden sind; auch die Hauptpflichten sind identisch formuliert (vgl. Art. 15, 16 ZDG und Art. 12, 13 KDG).

45 Vgl. Art. 54 ZDG und Art. 25 KDG. 
tet. Art. 52 Teil 1 ZDG nennt als Ziel dieser Garantien die Erhöhung der Motivation zur effektiven Erfüllung ihrer Dienstpflichten und die Festigung der Stabilität des Fachkräftebestands des Staatsdienstes.

In der russischen arbeitsrechtlichen und verwaltungsrechtlichen Literatur ist umstritten, welche Rechtsnatur die Normen des Zivildienstgesetzes haben. Einige Vertreter der Verwaltungsrechtswissenschaft wenden sich gegen einen arbeitsrechtlichen oder vertraglichen Charakter der Dienstverhältnisse der Staatsbediensteten. ${ }^{46}$ In der Arbeitsrechtswissenschaft wird hingegen vertreten, daß zwischen Staatsbediensteten und ihren Dienstherren dauerhafte, nach arbeitsrechtlicher Regulierung verlangende Beziehungen entstehen. Die Annahme von öffentlich-rechtlichen oder schwer einzuordnenden „dienstlichen“ Verhältnissen mit gemischt öffentlich- und privatrechtlichen Charakter wird für ein unnötiges und kompliziertes Konstrukt gehalten. ${ }^{47}$

Vorzugswürdig erscheint eine vermittelnde Ansicht: Die Dienstverhältnisse der „zivilen Staatsbediensteten" sind komplexe Rechtsverhältnisse, die ihrer Natur nach aus verschiedenen, untrennbar miteinander verbundenen und sich gegenseitig bedingenden Elementen bestehen und die sowohl öffentlich- als auch privatrechtlichen Charakter haben. Diese Verbindung ist derart, daß ein privatrechtliches Verhältnis innerhalb eines öffentlich-rechtlichen Verhältnisses ab dem Zeitpunkt entsteht, ab dem der zivile Staatsbedienstete seinen Dienst bei seiner Dienststelle antritt. 48

Die gesetzlichen Bestimmungen lassen ebenfalls auf einen Mischcharakter zwischen öffentlichem und Privatrecht im Innenverhältnis schließen: Gemäß Art. 73 ZDG finden die "Gesetze und anderen normativen Akte“ der RF und der Subjekte der RF, die arbeitsrechtliche Regelungen enthalten, auf die mit dem ,zivilen Staatsdienst verbundenen Beziehungen“ insoweit Anwendung, als dieses Gesetz keine Regelungen enthält. Das ZDG ordnet damit die subsidiäre Geltung des Arbeitsrechts an. 49

46 Grishkovets, Problemy sootnosheniya norm administrativnogo i trudovogo prava pri regulirovanii otnosheniy v sfere gosudarstvennoy sluzhby (Probleme des Verhältnisses von Normen des Verwaltungs- und Arbeitsrechts bei der Regelung der Verhältnisse im Bereich des Staatsdienstes), Gosudarstvo i pravo 12/2002, S. 11 (24).

47 Yershova, Trudovyye pravootnosheniya gosudarstvennykh grazhdanskikh i munitsipal'nykh sluzhashchikh v Rossii (Die Arbeitsverhältnisse ziviler Staatsbediensteten und der Kommunalbediensteten in Russland), 2008, S. $10 \mathrm{f}$.

48 Chikanova, Primeneniye trudovogo zakonodatel'stva k sluzhebnym otnosheniyam na gosudarstvennoy grazhdanskoy sluzhbe: teoriya i praktika: Avtoreferat dissertatsii na soiskaniye uchenoy stepeni doktora yuridicheskikh nauk (Die Anwendung der Arbeitsgesetzgebung auf die Dienstverhältnisse im zivilen Staatsdienst: Theorie und Praxis: Autoreferat der Habilitationsschrift für die Erlangung des wissenschaftlichen Grades des Doktors der juristischen Wissenschaften), 2005, S. 9.

49 Die Subsidiarität erfasst nicht die Subsidiarität einzelner Normen, sondern die Subsidiarität kompletter Regelungsbereiche. Vgl. Chikanova, Pravovoye regulirovaniye sluzhebnykh otnosheniy na gosudarstvennoy grazhdanskoy sluzhbe: voprosy teorii i praktiki (Die rechtliche Regelung der Dienstverhältnisse im zivilen Staatsdienst: Fragen von Theorie und Praxis), Zhurnal rossiyskogo prava 2005, S. 61 (69). 
Das Arbeitsgesetzbuch der RF50 (ArbGB RF) bestimmt demgegenüber in Art. 11 Teil 7, daß auf zivile Staatsbedienstete und Kommunalbedienstete die Arbeitsgesetzgebung und andere arbeitsrechtliche Akte „mit den Besonderheiten“ Anwendung finden, die die Gesetze und andere normativen Akte der Föderation und der Subjekte der Föderation für zivile Staatsbedienstete und Kommunalbedienstete vorsehen. Damit geht das ArbGB RF im Unterschied zum ZDG davon aus, daß das ArbGB RF grundsätzlich umfassend auf den zivilen Staatsdienst und den Kommunaldienst Anwendung findet. 51

Obwohl öffentlich-rechtlich geregelt, weisen die Dienstverhältnisse der Staatsbediensteten grundsätzlich alle Merkmale eines Arbeitsverhältnisses auf. Die Staatsbediensteten können sich auf die in der Verf RF den Arbeitnehmern garantierten Rechte berufen und haben das Recht, sich gewerkschaftlich zu organisieren, ${ }^{52}$ wobei ihnen das „Einstellen der Dienstausübung zum Zweck der Regelung eines dienstlichen Streits“, d.h. ein Streik, jedoch verboten ist. ${ }^{53}$ Weiter können die Staatsbediensteten wie andere Arbeitnehmer auch gekündigt werden, d.h. eine Anstellung auf Lebenszeit ist auch bei unbefristeter Einstellung nicht garantiert.

Gegenüber „,normalen“ Arbeitsverhältnissen weist die Regelung der Dienstverhältnisse der Staatsbediensteten jedoch wesentliche Besonderheiten auf. An erster Stelle zu nennen sind insoweit diejenigen Merkmale der Dienstverhältnisse, die in der Literatur als Kennzeichen des besonderen Status der Staatsbediensteten genannt werden. ${ }^{54}$ Hierzu gehören die in Art. 14 und 15 ZDG festgelegten besonderen ,grundlegenden Rechte“ und „grundlegenden Pflichten“ von Staatsbediensteten. 55 Weiter gehören hierzu die in Art. 16 und 17 ZDG geregelten Beschränkungen und Verbote, die zivile Staatsbedienstete zu beachten haben. ${ }^{56}$ Gegenüber dem ArbGB RF sind in Art. 57 Teil 1 ZDG zusätzliche Disziplinarmaßnahmen geregelt, wie z.B. die Suspension vom Amt. Art. 21 ZDG sieht zudem ein Mindestalter für Staatsbedienstete von 18 Jahren sowie ein Höchstdienstalter von 65 Jahren vor.

50 Föderationsgesetz Nr. 197 vom 30. Dezember 2001 (SZRF 2002 Nr. 1 Art. 3), zuletzt geändert durch Föderationsgesetz Nr. 80 vom 7. Mai 2009 (SZRF Nr. 19 Art. 2270).

51 Für den Militärdienst hingegen bestimmt in Art. 11 Abs. 8 ArbGB RF, daß sich die Arbeitsgesetzgebung auf die Militärangehörigen nicht erstreckt.

52 Zaytseva, Trudovaya pravosub'yektnost' grazhdanskikh gosudarstvennykh sluzhashchikh (Subjektivrechtliche Stellung der zivilen Staatsbediensteten), Nauchnyye trudy MGYUA 2007 Nr. 3 S. 480, 481.

53 Vgl. für zivile Staatsbedienstete Art. 17 Teil 1 Punkt 15 ZDG, für Kommunalbedienstete Art. 14 Teil 1 Punkt 1 KDG.

54 Zaytseva, Trudovaya pravosub'yektnost' grazhdanskikh gosudarstvennykh sluzhashchikh (Fußn. 52), S. 490 ff.

55 Anspruch auf Schutz des eigenen Lebens und der eigenen Gesundheit einschließlich von Leben und Gesundheit seiner Familie, Pflicht zur Achtung der Verfassung, der Gesetze und anderer normativer Akte, Pflicht zur Ausführung der Weisungen der Vorgesetzten, usw.

56 Grundsätzliches Erfordernis der russischen Staatsbürgerschaft, Verbot, gegen Entgelt Mitglied des Verwaltungsorgans einer Handelsgesellschaft zu sein, usw. 
Ein weiterer wesentlicher Unterschied der Dienstverhältnisse gegenüber einem „,normalen“ Arbeitsverhältnis ist, daß das Dienstverhältnis eines zivilen Staatsbediensteten durch den Akt der Berufung in das Amt (Verwaltungsakt) und den Abschluss des „Dienstkontrakts“ entsteht. ${ }^{57}$ Der Dienstkontrakt ist kein Arbeitsvertrag i.S.d. ArbGB RF. Der Akt der Berufung in das Amt geht dabei dem Abschluss des Dienstkontrakts voraus und bildet dessen Grundlage (Art. 26 Teil 1 ZDG). Der Abschluss eines „Dienstkontrakts“ an Stelle eines normalen Arbeitsvertrages wurde erstmals durch das ZDG eingeführt. ${ }^{58}$ In der Literatur wird teilweise davon ausgegangen, daß der Terminus gewählt wurde, um das Dienstverhältnis vom gewöhnlichen Arbeitsverhältnis abzugrenzen und die Wortwahl (,dienen“) den besonderen Über-/Unterordnungscharakter in diesem Verhältnis zum Ausdruck bringt. 59 Vom Arbeitsvertrag nach dem ArbGB RF unterscheidet sich der Dienstkontrakt nach dem ZDG dadurch, daß weit mehr zwingende Vorgaben für seinen Inhalt vorgesehen sind. ${ }^{60}$ Zudem sind in Kapitel 6 ZDG („Gründe und Folgen der Beendigung des Dienstkontrakts“) mehr Gründe für die Beendigung des Dienstkontrakts genannt als im entsprechenden Kapitel 13 des ArbGB RF. Zusätzliche Beendigungsgründe sind z.B. der Verlust der russischen Staatsangehörigkeit oder die Versetzung in den Ruhestand. Viele der genannten Beendigungsgründe entsprechen allerdings denen des ArbGB RF. In der Literatur wird kritisiert, daß das ZDG die Beendigungsgründe des ArbGB RF lediglich dupliziere und nicht auf die Besonderheit des Staatsdienstes Rücksicht nehme. 61

57 Chikanova, Pravovoye regulirovaniye sluzhebnykh otnosheniy na gosudarstvennoy grazhdanskoy sluzhbe (Fußn. 49), S. 64.

58 Das am 31. Januar 2005 außer Kraft getretene Staatdienstgrundlagengesetz 1995 legte hingegen in Art. 21 Punkt 6 noch fest, daß mit Staatsbediensteten Arbeitsverträge geschlossen werden.

59 Osin, Soderzhaniye, forma i osobennosti zaklyucheniya sluzhebnogo kontrakta (Inhalt, Form und Besonderheiten des Abschlusses des „Dienstkontrakts“), Trudovoye pravo 5/2007, S. 63, 64. Allerdings war von 1990 bis 2002 der Abschluss von „Kontrakten“ als besondere Art des Arbeitsvertrags auch im ArbGB RF vorgesehen. Diese „Kontrakte“, die das seit Februar 2002 geltende neue ArbGB RF nicht mehr kennt, unterschieden sich von normalen Arbeitsverträgen durch den besonderen Charakter der Aufgaben des Arbeitnehmers, der im Kontrakt schriftlich festzuhalten war (ein generelles Schriftformerfordernis für Arbeitsverträge ist erst durch das ArbGB RF eingeführt) und der die Vereinbarung zusätzlicher Befristungs- und Kündigungsgründe über die ansonsten gesetzlich zulässigen hinaus gestattete, vgl. Panina, in: Internationales Zentrum für finanzwirtschaftliche Entwicklung (Hrsg.), Kommentariy k Trudovomu kodeksu Rossiyskoy Federatsii (Kommentar zum Arbeitsgesetzbuch der Russischen Föderation), 2002, S. 161.

60 Allerdings ist die Vertragsfreiheit nicht ausgeschlossen. Wie auch das ArbGB RF in Art. 58 Teil 4, sieht Art. 24 Teil 4 Punkt 5 ZDG vor, daß die Parteien weitere Vertragsbedingungen aufnehmen können, sofern diese die Stellung des zivilen Staatsbediensteten nicht gegenüber den gesetzlichen Bestimmungen verschlechtern; vgl. auch Chikanova, Primeneniye trudovogo zakonodatel'stva k sluzhebnym otnosheniyam na gosudarstvennoy grazhdanskoy sluzhbe (Fußn. 48), S. 31.

61 Chikanova, Primeneniye trudovogo zakonodatel'stva k sluzhebnym otnosheniyam na gosudarstvennoy grazhdanskoy sluzhbe (Fußn. 48), S. 15 f., 23, 35; Osin, Soderzhaniye, forma i osobennosti zaklyucheniya sluzhebnogo kontrakta (Fußn. 59), S. 63, 73. 


\section{b) Status der Kommunalbediensteten}

Die Grundlagen der Rechtsstellung der Kommunalbediensteten sind im Föderationsgesetz Nr. 131 vom 6. Oktober 2003 „Über allgemeine Prinzipien der Organisation der kommunalen Selbstverwaltung in der RF"62 und im KDG geregelt. Mit den Kommunalbediensteten werden allerdings Arbeitsverträge und nicht „Dienstkontrakte“ abgeschlossen (Art. 2 Teil 1 KDG). Das KDG enthält jedoch einige vom allgemeinen Arbeitsrecht des ArbGB RF63 abweichende Besonderheiten, z.B. zusätzliche Gründe für die Beendigung der Arbeitsverhältnisse sowie Beschränkungen und Verbote für Kommunalbedienstete. Insoweit bestehen starke Ähnlichkeiten zu den Regelungen für zivile Staatsbedienstete im ZDG. Dies entspricht dem Grundsatz der „Wechselbeziehungen“ zwischen Staatsdienst und Kommunaldienst (Art. 5 KDG).

\section{c) Verfassungsrechtliche Zulässigkeit der Statusregelungen}

Verfassungsrechtliche Fragen hat der Sonderstatus der Staats- und Kommunalbediensteten vor dem Hintergrund, daß die Verf RF einen solchen Status nicht kennt, vor allem dahingehend aufgeworfen, ob die für Staatsbedienstete geltenden Beschränkungen (insbesondere die Altersgrenze) gegenüber „,normalen“ Arbeitnehmern vor dem Hintergrund des Gleichheitssatzes (Art. 19 Teile 1 und 2 Verf RF), dem Recht auf gleichen Zugang zum Staatsdienst (Art. 32 Teil 4 Verf RF) und der in Art. 37 Teil 1 Verf RF garantierten Berufsfreiheit zulässig sind. Das VerfG RF hat dies bejaht und ausgeführt, daß zum Wesen des Staatsdienstes als professionelle Tätigkeit zur Erfüllung der Zuständigkeiten staatlicher Organe ein besonderer rechtlicher Status der Bediensteten gehört, dem der Staat durch besondere öffentlich-rechtliche Regelungen Rechnung tragen darf und muss. Der Eingriff in die genannten Grundrechte ist gerechtfertigt, da die entsprechenden Regelungen den besonderen Aufgaben und Organisationsprinzipien des Staatsdienstes Rechnung tragen und dessen Funktionsfähigkeit sowie ein hohes Vollzugsniveau sicherstellen. ${ }^{64}$

62 SZRF Nr. 40 Art. 3822, zuletzt geändert durch das Föderationsgesetz Nr. 90 vom 7. Mai 2009 (SZRF Nr. 19 Art. 2280).

63 Ebenso wie für die zivilen Staatsbediensteten bestimmt Art. 11 Teil 7 ArbGB RF auch für Kommunalbedienstete, daß die Arbeitsgesetzgebung und andere arbeitsrechtliche Akte „mit den Besonderheiten" Anwendung finden, die Gesetze und andere normativen Akte der Föderation und der Subjekte der Föderation für den Staatsdienst und den Kommunaldienst vorsehen.

64 Entscheidung Nr. 233-O des VerfG RF vom 3. Oktober 2002. 
4. Erfordernis einer besonderen sozialen Sicherung der Beamten im Alter aufgrund der Besonderheiten der Stellung der Staatsbediensteten

Zivilen Staatsbediensteten und Kommunalbediensteten sowie ihren Familien wird durch das ZDG und das KDG sozialer Schutz bei Krankheit und im Alter (bzw. als Hinterbliebene) „nach den Föderationsgesetzen“ garantiert (Art. 14 Teil 1, Art. 52 Teil 1 ZDG ${ }^{65}$ ). Diese Garantien sind allerdings verfassungsrechtlich nicht stärker abgesichert als der soziale Schutz aller Menschen in Russland (Grundrecht auf soziale Sicherheit, Art. 39 Verf RF). Ein Alimentationsprinzip 66 zugunsten von Staatsbediensteten kennt die Verf RF nicht. In der Literatur wird zudem vertreten, daß bei der Ausgestaltung der Altersversorgung von Staatsbediensteten das Prinzip der Einheitlichkeit des Staatsdienstes zu beachten sei. ${ }^{67}$ Allerdings ist dieses Prinzip nur einfachgesetzlich geregelt. ${ }^{68}$

\section{Ausgestaltung der Altersabsicherung von Staatsbediensteten}

1. Grundlegende Unterschiede zwischen den Alterssicherungssystemen für zivile Staatsbedienstete und Kommunalbedienstete und dem allgemeinen Alterssicherungssystem für Arbeitnehmer

\section{a) Allgemeines System der Alterssicherung für Arbeitnehmer}

Bis zum Jahr 2002 haben über $90 \%$ der Rentner ihre Renten aufgrund des Gesetzes Nr. 340-1 vom 20. November 1990 „Über die staatlichen Renten in der Russischen Föderation" 69 erhalten. 70 Durch die internationale Arbeitsorganisation wurde dieses Ge-

65 Für Kommunalbedienstete vgl. Art. 11 Teil 1 KDG.

66 Ein Alimentationsprinzip ist in der russischen Rechtstradition in anderem Zusammenhang bekannt. Unter „Sozialalimentation“ wurde in der sozialrechtlichen Literatur der Sowjetunion verstanden: die Zurverfügungstellung aller Arten der kostenlosen sozialen Versorgung - aus dem Fonds der Sozialversorgung und ohne vertragliche Grundlage - im Zusammengang mit einer Arbeit, jedoch nicht als Gegenleistung für diese, sondern auf Grundlage gerechter Fürsorge im Umfang des normalen Lebensstandards, wie er dem jeweils aktuellen Stand der Entwicklung der sowjetischen Gesellschaft entsprach. Vgl. Machul'skaya/Gorbacheva, Pravo sotsial'nogo obespecheniya (Das Recht der sozialen Sicherheit), 2000, S. 30.

67 Vgl. hierzu auch unten III.

68 Art. 3 Teil 1 Abs. 5 SDSG, Art. 4 Punkt 2 ZDG.

69 Vedomosti SND i WS RSFSR Nr. 27 Art. 351, zuletzt geändert durch Föderationsgesetz Nr. 155 vom 27. November 2001 (SZRF Nr. 49 Art. 4561), aufgehoben durch Art. 31 Punkt 2 Arbeitsrentengesetz mit dessen Inkrafttreten am 1. Januar 2002.

70 Savost'yanova, in: Gusov, Pravo sotsial'nogo obespecheniya Rossii (Das Recht der sozialen Sicherheit Russlands), 4. Aufl. 2008, S. 213. 
setz für gut befunden, da internationale Erfahrungen berücksichtigt wurden. ${ }^{71}$ Das hohe Leistungsniveau der Renten wurde allerdings durch vielfältige Änderungen von 1992 bis 2001 stark gesenkt und das System weitgehend umgestaltet. Insbesondere wurden die Rentenanpassungen verringert und das Mindestniveau der Renten gesenkt. ${ }^{72}$

Im Jahr 2002 wurde in Russland eine Rentenreform durchgeführt. Zu den Hauptzielen der Reform gehörte auch die Umgestaltung des Umlagesystems in ein gemischtes System mit kapitalgedeckten Elementen und die Stärkung des Versicherungsprinzips. ${ }^{73}$ Das Älterwerden der Gesellschaft war ebenfalls Anlass für die Reformpläne. Als Ergebnis der Reformdiskussion traten 2002 folgende Gesetze in Kraft: Das Föderationsgesetz Nr. 167 „Über die Rentenpflichtversicherung“ vom 15. Dezember 200174 (RVG), das Föderationsgesetz Nr. 173 „Über die Arbeitsrenten in der Russischen Föderation“ vom 17. Dezember 2001 (ARG) ${ }^{75}$ und das Föderationsgesetz Nr. 166 „Über die staatliche Pensionsversorgung“" vom 15. Dezember 2001 (PVG) ${ }^{76}$. Mit dieser Reform wurde ein neues Verfahren zur Finanzierung der Sozialversicherung eingeführt, dessen wesentlicher Inhalt der Übergang von einem Beitragssystem zur einheitlichen Sozialsteuer, die Arbeitgeber für ihre Arbeitnehmer in den Sozialversicherungsfonds der RF einzahlen, war (Kapitel 24 von Teil 2 des Steuerkodexes der RF) ${ }^{77}$.

Seit 2002 bestehen in der RF zwei Rentensysteme: Die Arbeitsrenten werden aufgrund des ARG und die staatlichen Altersversorgungsleistungen aufgrund des PVG geleistet. Beide Systeme unterscheiden sich durch die Art der Finanzierung. Während die Arbeitsrenten vom Rentenfonds aus Mitteln von Versicherungsbeiträgen und aus der einheitlichen Sozialsteuer finanziert werden, werden die Altersversorgungsleistungen aus Mitteln des allgemeinen Staatshaushalts gezahlt.

Aktuell wird in Russland das Sozialsystem erneut reformiert. Ab dem 1. Januar 2010 werden die einheitliche Sozialsteuer abgeschafft und die Versicherungen wieder auf ein reines Beitragssystem umgestellt. ${ }^{78}$

Die Arbeitsrenten unterteilen sich in Altersrenten, Invaliditätsrenten und Hinterbliebenenrenten. Einen Anspruch auf Arbeitsrente haben Personen, die in der Rentenversi-

71 Savost'yanova, in: Gusov, Pravo sotsial'nogo obespecheniya Rossii (Fußn. 70), S. 213.

72 Savost'yanova, a.a.O.; Zakharov/Tuchkova, Pravo sotsial'nogo obespecheniya Rossii (Das Recht der sozialen Sicherheit Russlands), 2005, S. 219.

73 Roik, Pensionnaya sistema Rossii: istoriya, problemy i puti sovershenstvovaniya (Das Rentensystem Russlands - Geschichte, Probleme und Wege zur Vollendung), 2007, S. 107.

74 SZRF Nr. 51 Art. 4832, zuletzt geändert durch Föderationsgesetz Nr. 213 vom 24. Juli 2009 (SZRF 2009 Nr. 30 Art. 3739).

75 SZRF Nr. 52 Art. 4920, zuletzt geändert durch Föderationsgesetz Nr. 213/2009 (Fußn. 74).

76 SZRF Nr. 51 Art. 4831, zuletzt geändert durch Föderationsgesetz Nr. 213/2009 (Fußn. 74).

77 Föderationsgesetz Nr. 117 vom 5. August 2000 (SZRF Nr. 32 Art. 3340), zuletzt geändert durch Föderationsgesetz Nr. 213/2009 (Fußn. 74).

78 Vgl. Rossiyskaya Gazeta, Zentrale Ausgabe Nr. 4924 vom 4. Juni 2009 (unter http://www.rg.ru/2009/06/04/minimum.html). Die Änderungen erfolgten durch das Föderationsgesetz Nr. 212 vom 24. Juli 2009 (SZRF Nr. 30 Art. 3738) und das Föderationsgesetz Nr. 213/2009 (Fußn. 74). 
cherung pflichtversichert sind. Nach dem ARG teilt sich die Arbeitsrente auf in einen „Basisteil“ (ab 2010 „feste Basishöhe des Versicherungsteils“) ${ }^{79}$, einen „Versicherungsteil“ und einen „kapitalgedeckten Teil“. Der Basisteil hat eine feste Höhe und wird bis Ende 2009 aus den laufenden Einnahmen der einheitlichen Sozialsteuer finanziert. ${ }^{80}$ Die Höhe des Basisteils ist unabhängig von der Höhe des im Laufe der Erwerbstätigkeit erzielten Einkommens und beträgt gemäß Art. 14 Punkt 1 ARG einheitlich für alle Rentner 1.950 Rubel (zum Vergleich bei Inkrafttreten des Gesetzes in 2002: 450 Rubel, in 2005: 900 Rubel $^{81}$, ab 1. Dezember 2009: 2.562 Rubel $^{82}$ ), ab dem 80ten Lebensjahr 3.900 Rubel (zum Vergleich bei Inkrafttreten des Gesetzes in 2002: 900 Rubel, in 2005: 1.800 Rubel, ab 1. Dezember 2009: 5.124 Rubel). ${ }^{83}$ Die Höhe des Versicherungsteils richtet sich gemäß Art. 14 Punkt 5 ARG nach dem früheren Einkommen des Versicherten und wird aus den laufenden Einnahmen der Beiträge zur Rentenversicherung finanziert, die von den Arbeitgebern (allein) für ihre Arbeitnehmer an den Rentenversicherungsfonds der RF eingezahlt werden. Von den Beiträgen zum Rentenversicherungsfonds ( $14 \%$ des Einkommens bis zur Beitragsbemessungsgrenze ${ }^{84}$ ) fließt allerdings für 1967 und später geborene Versicherte ein Anteil (6 \%) des beitragspflichtigen Einkommens nicht in die auf Umlage basierte Finanzierung des Versicherungsteils der laufenden Renten, sondern wird auf ein ,persönliches Konto“ eingezahlt, wo es vom Rentenversicherungsfonds verwaltet und für die Versicherten angelegt wird. Auszahlungen aus

79 Von 2010 an wird an Stelle des Basisteils der Arbeitsrenten eine „feste Basishöhe des Versicherungsteils“ der Arbeitsrenten eingeführt, vgl. die entsprechende Neufassung von Art. 14 ARG durch Art. 28 Punkt 10 des Föderationsgesetzes Nr. 213/2009 (Fußn. 74).

80 Der Steuersatz der einheitlichen Sozialsteuer, die allein vom Arbeitgeber zu tragen ist, liegt seit Einführung der Sozialsteuer im Jahr 2002 bei $26 \%$, wobei der Steuersatz für Einkommen über 280.000 Rubel ab dieser Summe auf 5,5\% und schließlich ab 600.000 Rubel auf $2 \%$ sinkt, vgl. Art. 241 Steuerkodex RF. In den Basisanteil der Arbeitsrente fließt dabei ca. ein Fünftel der Sozialsteuer ( $6 \%$ bis zu einem Einkommen von 280.000 Rubel), vgl. Savost'yanova, in: Gusov, Pravo sotsial'nogo obespecheniya Rossii (Fußn. 70), S. 45.

81 Vgl. ARG idF des Föderationsgesetzes Nr. 3 vom 3. Februar 2005 (SZRF Nr. 8 Art. 605).

82 Vgl. ARG idF des Föderationsgesetzes Nr. 72 vom 28. April 2009 (SZRF Nr. 18 Art. 2152).

83 Höhere Basisrenten sind bei Zusammenleben mit einem arbeitsunfähigen Familienmitglied, für Invalide und ab dem 80ten Lebensjahr vorgesehen (Art. 14 Punkt 4 ARG).

84 Bis Ende 2009 ist der Begriff „Beitragsbemessungsgrenze“ nicht ganz exakt: Ähnlich wie bei der bis dahin noch vorgesehenen Sozialsteuer (vgl. Fußn. 80) sinkt der Beitragssatz degressiv. Die $14 \%$ gelten bis zu einem Jahreseinkommen von 280.000 Rubel, vgl. Art. 22 Punkt 2 PVG in der bis Ende 2009 geltenden Fassung. Ab 2011 hingegen liegt eine ,echte“ Beitragsbemessungsgrenze in Höhe von 415.000 Rubel vor, vgl. Art. 8 Föderationsgesetz Nr. 212/2009 (Fußn. 78). Der Beitrag beträgt ab $201126 \%$, wobei $10 \%$ künftig an Stelle der Sozialsteuer für die Finanzierung der ,festen Basishöhe des Versicherungsteils“" verwendet und die übrigen $16 \%$ den persönlichen Versicherungskonten gutgeschrieben werden, d.h. dem reinen Versicherungsteil der Arbeitsrenten und für ab dem Jahr 1967 geborene Versicherte auch dem kapitalgedeckten Anteil (6 \%) der Arbeitsrente zu Gute kommen, vgl. Art. 22 Punkt 2.1 PVG sowie das Föderationsgesetz Nr. 27 vom 1. April 1996 „Über das individuelle (personifizierte) Konto im System der Rentenpflichtversicherung“" (SZRF Nr. 14 Art. 1401), jeweils idF des Föderationsgesetzes Nr. 213/2009 (Fußn. 74). Für 2010 gelten Übergangsregelungen. 
dem kapitalgedecktem Anteil beginnen gemäß Art. 32 Punkt 2 ARG erst im Jahr 2013. Bis dahin besteht die Rente nur aus dem Basis- und dem Versicherungsteil. ${ }^{85}$

Durch das Föderationsgesetz Nr. 56 vom 30. April 2008 ,Über zusätzliche Versicherungsbeiträge für den kapitalgedeckten Anteil der Arbeitsrente und über die staatlichen Förderung der Kapitalbildung" ${ }^{\text {" } 86}$ wurde eine zusätzliche staatliche Förderung des kapitalgedeckten Elements eingeführt. Wenn Arbeitnehmer innerhalb eines Zeitraums von fünf Jahren nach Inkrafttreten des Gesetzes am 1. Oktober 2008 beginnen, freiwillig zusätzliche Beiträge für den kapitalgedeckten Teil der Altersrente leisten, zahlt der Staat ebenfalls zehn Jahre lang einen entsprechend hohen Beitrag wie der jeweilige Arbeitnehmer in dessen persönliches Rentenkonto an Beiträgen zur Kapitaldeckung ein, jedoch nicht mehr als 12.000 Rubel pro Jahr.

Seit einigen Jahren beginnt sich zudem auf Grundlage des am 7. Mai 1998 erlassenen Föderationsgesetzes Nr. 75 „Über private Rentenfonds“87 ein zusätzliches Angebot für private Rentenversicherungen auf kapitalgedeckter Basis herauszubilden.

\section{b) Alterssicherung der zivilen Staatsbediensteten}

Für Angehörige des zivilen Staatsdienstes der Föderation und des Staatsdienstes der Subjekte der Föderation garantieren Art. 14 Teil 1 Punkt 18 und Art. 52 Teil 1 Punkt 11 ZDG einen Anspruch auf eine Pensionsversorgung nach den Föderationsgesetzen.

Die Alterspensionen der zivilen Staatsbediensteten der Föderation sind heute im PVG geregelt. Das am 1. Januar 2002 in Kraft getretene PVG führte erstmals gesetzliche Pensionsansprüche für Staatsbedienstete ein. Bis zum Inkrafttreten des PVG wurden Staatsbediensteten gemäß dem Erlaß des Präsidenten der RF Nr. 854 vom 16. August 1995 ,Über einige soziale Garantien für Bürger, die Staatsämter der Russischen Föderation ausüben und für föderale Staatsbedienstete" 88 (Präsidialerlaß Nr. 854/1995) monatliche Zuschläge zu „,normalen“ Arbeitsrenten gezahlt. Allerdings stellen auch die Pensionen für zivile Staatsbedienstete der Föderation nach dem heutigen PVG keine völlig eigenständige Pensionsleistung dar. Ein Anspruch auf die Pension besteht vielmehr nur bei gleichzeitigem Bestehen eines Anspruchs auf Arbeitsrenten nach dem ARG. Daher haben die Pensionen für die zivilen Staatsbediensteten bis heute den Charakter eines Zuschlags (einer Zulage) zur Arbeitsrente. ${ }^{89}$ Dies hängt damit zusammen, daß zivile

85 Zurabov, Kommentariy k pensionnomu zakonodatel'stvu Rossiyskoy Federatsii (Kommentar zur Pensionsgesetzgebung der Russischen Föderation), 2007, S. 936.

86 SZRF Nr. 18 Art. 1943.

87 SZRF Nr. 19 Art. 2071, zuletzt geändert durch Föderationsgesetz Nr. 160 vom 18. Juli 2009 (SZRF Nr. 29, Art. 3619).

88 SZRF Nr. 34 Art. 3442, zuletzt geändert durch Erlaß vom 25. Juli 2006 (SZRF Nr. 31 Art. 3459).

89 Nazarov, Gosudarstvennyye grazhdanskiye sluzhashchiye: pravo na pensiyu (Zivile Staatsbedienstete: Ihr Recht auf eine Pension), Spravochnik kadrovika 3/2008, S. 113, 114. 
Staatsbedienstete während ihrer Dienstzeit wie andere Arbeitnehmer in der allgemeinen Rentenversicherung nach dem RVG pflichtversichert sind. ${ }^{90}$

Hervorzuheben ist, daß das PVG nicht nur die Pensionsansprüche von Staatsbediensteten regelt. Vielmehr ist das PVG in Abgrenzung zum ARG dahingehend konzipiert, daß es sämtliche staatliche, d.h. nicht durch Beitragszahlungen an den Rentenversicherungsfonds, sondern aus dem allgemeinen Staatshaushalt finanzierte Altersversorgungsleistungen regelt. Nach dem PVG werden folgende Altersversorgungsleistungen gezahlt (vgl. Art. 5 Punkt 1 i. V. m. Art. 2 und 4 PVG):

- Staatsbedienstetenpensionen für föderale zivile Staatsbedienstete;

- Pensionen für invalide Militärangehörige sowie die Hinterbliebenen von Militärangehörigen ${ }^{91}$;

- Altersrenten für Bürger, die Opfer einer atomaren oder technischen Katastrophe geworden sind;

- Invaliditätsrenten für Bürger, die Opfer einer atomaren oder technischen Katastrophe geworden sind, am Zweiten Weltkrieg teilgenommen oder während der Zeit der Blockade in Leningrad gelebt haben;

- Hinterbliebenenrenten für Hinterbliebene von Opfern atomarer oder technischer Katastrophen;

- Sozialrenten für arbeitsunfähige Bürger, die keinen Anspruch auf Arbeitsrenten nach dem ARG haben (z.B. wegen Behinderung seit der Kindheit).

Hinterbliebene von zivilen Staatsbediensteten haben keine Pensionsansprüche nach dem PVG. Ihre Versorgung richtet sich wie die Hinterbliebenenversorgung von ,normalen“" Arbeitnehmern allein nach dem ARG, d.h. sie erhalten keine, die Arbeitsrente aufstockende Pension.

\section{c) Staatsbedienstete der Subjekte der Föderation und Kommunalbedienstete}

Die Geltung des Pensionsversorgungsgesetzes erstreckt sich nicht auf Staatsbedienstete der Subjekte der RF und auf Kommunalbedienstete. ${ }^{92}$ Art. 7 Teil 4 PVG bestimmt,

90 Nazarov, a.a.O.

91 Im Übrigen sind die Pensionen von Militärangehörigen rein öffentlich-rechtlich geregelt durch das Gesetz der RF vom 12. Februar 1993 Nr. 4468-1 „Über die Pensionsversorgung der Personen, die Dienst in Militär, den Organen des Inneren, der staatlichen Feuerwehr, den Organen zur Kontrolle des Drogenhandels und den Strafverfolgungsorganen leisten, und ihrer Familien“, Vedomosti SND i WS RSFSR Nr. 9 Art. 328, zuletzt geändert durch Föderationsgesetz Nr. 213/2009 (Fußn. 74). Militärangehörige erhalten ausschließlich Pensionsleistungen und sind nicht in der Rentenversicherung der Arbeitnehmer versichert. In der Literatur wird diese Altersversorgung als Ausdruck eines Alimentationsprinzips verstanden: Koryakin, Pravo sotsial'nogo obespecheniya voyennosluzhashchikh, grazhdan, uvolennykh s voyennoy sluzhby, i chlenov ikh semey (Das Recht der sozialen Sicherheit der Militärangehörigen und der Personen, die aus dem Militärdienst ausgeschieden sind, und ihrer Familien), 2005, S. 41. 
daß sich die Voraussetzungen für den Bezug dieser Pensionen nach den Gesetzen und anderen normativen Akten der Subjekte der RF und nach den normativen Akten der Organe der kommunalen Selbstverwaltung richten. Es gelten daher auf Ebene der Subjekte der RF jeweils eigenständige Gesetze und normative Akte über die Pensionsversorgung der Staatsbediensteten der Subjekte der RF und der Kommunalbediensteten.

Die Subjekte der RF haben bei der Ausgestaltung der Pensionsversorgung ihrer Staatsbediensteten das in Art. 4 Punkt 2 ZDG verankerte Prinzip der Einheitlichkeit der rechtlichen und organisatorischen Grundlagen des zivilen Staatsdienstes auf föderaler und auf Subjektebene zu beachten.

Die Organe der kommunalen Selbstverwaltung haben bei der Ausgestaltung der Pensionsversorgung der Kommunalbediensteten das in Art. 3 Teil 1 Abs. 6 SDSG, Art. 7 ZDG und Art. 5 KDG verankerte Prinzip der „Wechselbeziehungen“ zwischen Staatsund Kommunaldienst zu beachten. Als Ausfluß dieses Prinzips verlangt Art. 7 Punkt 5 ZDG ${ }^{93}$ die Vergleichbarkeit der sozialen Garantien und Art. 7 Punkt 6 ZDG ${ }^{94}$ der Pensionsversorgung von Staats- und Kommunalbediensteten. Diese grundsätzlichen Vorgaben für die Ausgestaltung der sozialen Garantien von Kommunalbediensteten engt Art. 24 Teil 1 KDG darüber hinaus dahingehend ein, daß auf deren Pensionsversorgung „,in vollem Umfang“ entsprechende Rechte wie für zivile Staatsbeamte der RF und ihrer Subjekte vorzusehen sind. ${ }^{95}$ Weiter bestimmt Art. 24 Teil 2 KDG, daß die Höhe der Pension von Kommunalbediensteten in einem Subjekt der RF die Höhe der Pension, die in dem betreffenden Subjekt der RF für ein Amt gleichen Rangs des zivilen Staatsdienstes vorgesehen ist, nicht überschreiten darf.

Die Subjekte der RF und die Organe der kommunalen Selbstverwaltung haben diese föderationsrechtlichen Vorgaben umgesetzt und für ihre Bediensteten eine Pensionsversorgung entsprechend der für zivile Staatsbedienstete geregelt.

\section{Voraussetzungen des Erhalts einer Alterspension für zivile Staatsbedienstete}

Die folgende Darstellung von Leistungsvoraussetzungen und Leistungsumfang orientiert sich an den für zivile Staatbedienstete der Föderation geltenden Regelungen des PVG. Im Hinblick auf die entsprechenden Regelungen auf Ebene der Subjekte der RF und auf kommunaler Ebene gelten diese Ausführungen jedoch entsprechend auch für den Staatsdienst auf diesen Ebenen.

92 Kozbanenko, Kommentariy k Zakonu „O gosudarstvennoy grazhdanskoy sluzhbe Rossiyskoy Federatsii“ (Kommentar zum Gesetz „Über den zivilen Staatsdienst der Russischen Föderation“), aufbereitet für die juristische Datenbank KonsultantPlus, Art. 14.

93 Identisch mit Art. 5 Punkt 5 KDG.

94 Identisch mit Art. 5 Punkt 6 KDG.

95 Zuletzt geändert durch Föderationsgesetz Nr. 156 „Über die Aufnahme von Änderungen in einzelne gesetzliche Akte der Russischen Föderation zu Frage der Pensionsversorgung“"vom 22. Juli 2008 (SZRF Nr. 30 Art. 3612). 
Art. 7 PVG regelt für zivile Staatsbedienstete folgende Voraussetzungen für den Bezug einer (die Altersrente ergänzenden) Alterspension:

- Die Dienstzeit im Staatsdienst ${ }^{96}$ darf nicht weniger als 15 Jahre betragen haben. Sie berechnet sich nach dem Erlaß Nr. 1413 des Präsidenten der RF vom 17. Dezember 2002 „Über die Feststellung des Verzeichnisses der Behörden und der Dienstzeiten, die bei der Berechnung der für die Alterspension maßgeblichen Dienstzeit zu berücksichtigen sind“97 und nach der Verordnung Nr. 570 der Regierung der RF vom 15. September 2003 „Über das Verfahren der Berücksichtigung von Dienstzeiten in föderalen Staatsämtern und Ämtern des föderalen Staatsdienstes und anderen Ämtern, die vom Präsidenten der Russischen Föderation bestimmt sind, bei der Berechnung der für die Alterspension maßgeblichen Dienstzeit" $" 98$.

- Der zivile Staatsbedienstete muss grundsätzlich mindestens zwölf volle Kalendermonate ${ }^{99}$ im Staatsdienst gestanden haben und aus einem der in Art. 7 Teil 1 PVG genannten Gründen aus dem Dienst ausgeschieden sein, z.B. wegen Erreichens der Altersgrenze von 65 Jahren oder bei befristetem Dienstkontrakt wegen Auslaufens der Frist.

- Hervorzuheben ist, daß die Voraussetzung des Ausscheidens aus dem Dienst ein wesentliches Unterscheidungsmerkmal gegenüber den für allgemeine Arbeitsrenten geltenden Leistungsvoraussetzungen bildet. Denn ein Anspruch auf Zahlung der allgemeinen Arbeitsrente nach dem ARG besteht bei Eintritt der Anspruchsvoraussetzungen (insbesondere bei Erreichen des Renteneintrittsalters) auch dann, wenn der betreffende Arbeitnehmer weiter in seinem bisherigen Beruf tätig bleibt. Er erhält dann die Rente zusätzlich zu seinem normalen Gehalt. Der Pensionsanspruch der zivilen Staatsbediensteten wird bei fortgesetzter beruflicher Tätigkeit hingegen nur dann erworben, wenn es sich um eine Arbeitstätigkeit auBerhalb des Staatsdienstes handelt.

- Schließlich setzt der Anspruch auf Alterspension nach Art. 7 Punkt 2 PVG voraus, daß dem zivilen Staatsbediensteten einer Arbeitsrente oder eine Invaliditätsrente nach dem ARG bewilligt wurde. Erfüllt ein ziviler Staatsbediensteter daher nicht zugleich alle Anspruchsvoraussetzungen für den Erhalt einer Arbeitsrente nach dem ARG, so hat er auch dann keinen Anspruch auf (ergänzende) Alterspension nach dem PVG, wenn er alle übrigen in Art. 7 PVG genannten An-

96 Maßgeblich ist die frühere Wahrnehmung eines gemäß Art. 8 SDSG i.V.m. den jeweiligen Ausführungsbestimmungen für die betreffende Art des Staatsdienstes zum Staatdienst zählenden Amtes. Zu den zum zivilen Staatsdienst zählenden Ämtern vgl. den Präsidialerlaß Nr. 1574/2005.

97 SZRF Nr. 51 Art. 5063, zuletzt geändert durch Erlaß Nr. 931 vom 6. August 2005 (SZRF Nr. 32 Art. 3275).

98 SZRF Nr. 38 Art. 3661, zuletzt geändert durch Verordnung Nr.7 vom 11. Januar 2005 (SZRF Nr. 3 Art. 197).

99 Krankheitszeiten o.ä. sind dabei unschädlich. 
spruchsvoraussetzungen erfüllt. 100 Die Anspruchsvoraussetzungen für den Erhalt der Altersrente sind nach Art. 7 ARG seit 1. Januar 2002 folgende: die Erfüllung der Wartezeit von fünf Versicherungsjahren ${ }^{101}$ und das Erreichen der Altersgrenze von 60 Jahren für Männer und 55 Jahren für Frauen.

Die Alterspension wird bewilligt und ausgezahlt von dem Tag an, ab dem der zivile Staatsbedienstete sie beantragt, jedoch nicht vor dem Ausscheiden aus dem Staatsdienst und nicht vor Bewilligung der Arbeitsrente nach dem ARG.

\section{Leistungsbemessung der Alterspension für zivile Staatsbedienstete}

Für zivile Staatsbedienstete ist die Höhe ihrer Pension in Art. 14 PVG geregelt. Danach erhalten zivile Staatsbedienstete der RF, soweit sie eine 15-jährige Dienstzeit aufweisen, eine Pension von $45 \%$ ihrer durchschnittlichen monatlichen Bezüge unter Abzug des Basis- und des Versicherungsanteils der Arbeitsrente ${ }^{102}$, die der Staatsbedienstete nach dem ARG erhält. Für jedes volle Kalenderjahr über die 15-jährige Mindestdienstzeit hinaus erhöht sich dieser Prozentsatz um jeweils $3 \%$ bis zu einer Höhe von maximal $75 \%$ der durchschnittlichen monatlichen Bezüge. ${ }^{103}$ Die Höhe der durchschnittlichen monatlichen Bezüge von Staatsbediensteten der RF berechnet sich dabei gemäß Art. 21 Punkt 1 PVG aus der Höhe ihrer durchschnittlichen Bezüge (Grundgehalt einschließlich Zulagen) in den letzten zwölf vollen Monaten, die dem Dienstzeitende vorausgehen. ${ }^{104}$ Art. 21 Punkt 2 PVG sieht zudem eine Obergrenze für die anzusetzende Höhe der Bezüge vor, die bis Ende 2008 bei dem 2,3-fachen des Grundgehalts

100 Kozbanenko, Kommentariy k Zakonu „O gosudarstvennoy grazhdanskoy sluzhbe Rossiyskoy Federatsii“ (Fußn. 92), Art. 14.

101 Vor Inkrafttreten dieser Regelung wurde gemäß Art. 10 des Gesetzes Nr. 340-1 vom 20. November 1990 „Über die staatlichen Renten in der Russischen Föderation“ eine Lebensarbeitszeit von nicht weniger als 25 Jahren für Männer und nicht weniger als 20 Jahren für Frauen vorausgesetzt.

$102 \mathrm{Ab} 2010$ wird der Basisanteil in Art. 14 PVG nicht mehr als abzuziehend genannt, vgl. Art. 26 Föderationsgesetz Nr. 213/2009 (Fußn. 74). Eine inhaltliche Änderung ist damit jedoch nicht verbunden, da der bis 2009 aus der einheitlichen Sozialsteuer finanzierte Basisanteil mit Abschaffung der Sozialsteuer und Übergang zu einem reinen Beitragssystem künftig als „feste Basishöhe“ Teil des Versicherungsteils der Arbeitsrente wird.

103 Für zivile Staatsbedienstete der RF, die in den Regionen des „Hohen Nordens“ und in Regionen mit vergleichbar schwierigen Lebensbedingungen (Berg- und Wüstenregionen) leben, wird, solange der Wohnsitz in der betreffenden Region aufrechterhalten wird, eine um einen durch Verordnung der Regierung der RF festgelegten Regionskoeffizienten erhöhte Pension ausgezahlt (Art. 14 Punkt 2 ARG). Zu Einzelheiten der Leistungsbemessung vgl. Savost'yanova/Tuchkova/Zakharov, Kommentariy k novomu pensionnomu zakonodatel'stvu (Kommentar zur neuen Pensionsgesetzgebung: Artikelkommentar zum Föderationsgesetz „Über die Arbeitsrenten in der Russischen Föderation“ und zum Gesetz über die „Pensionsversorgung in der Russischen Föderation), 2003, Art. 7.

104 Alternativ kann nach Art. 21 Punkt 1 PVG auch auf die in den letzten zwölf Monaten vor Erreichen des Renteneintrittsalters nach dem ARG erhaltenen durchschnittlichen Bezüge abgestellt werden. 
lag. Durch das Föderationsgesetz Nr. 187 vom 18. Juli 2009105 wurde die Obergrenze auf das 2,8-fache des Grundgehalts angehoben.

Durch das Föderationsgesetz Nr. 156 vom 22. Juli $2008^{106}$ wurde Art. 14 um einen Punkt 3 ergänzt. Dieser sieht vor, daß Staatsbediensteten, die nach ihrem Ausscheiden eine andere (rentenbeitragspflichtige) Arbeitstätigkeit außerhalb des zivilen Staatsdienstes aufnehmen oder fortführen und hierdurch im Verlauf der Zeit zugleich die Höhe ihrer Arbeitsrente steigern, diese Steigerungen des Versicherungsanteils der Arbeitsrente nicht auf den Pensionsanspruch angerechnet werden. 107

Hervorzuheben ist weiter, daß der kapitalgedeckte Anteil der Altersrente nicht gemäß Art. 14 Punkt 1 PVG auf die Alterspension angerechnet wird. Dies entspricht dem in Art. 3 Punkt 4 PVG festgelegten Grundsatz, daß die Pensions- und Versorgungsleistungen unabhängig vom Bezug des kapitalgedeckten Teils der Altersrente nach dem ARG bewilligt und ausgezahlt werden. 108

\section{Anpassungen der Alterspension für zivile Staatsbedienstete}

Erhöhungen der Arbeitsrenten nach dem ARG wirken sich für die zivilen Staatsbediensteten nicht auf die Höhe ihres Gesamtversorgungsniveaus aus, da diese Erhöhung zu einer entsprechenden Kürzung der Pensionen nach dem PVG führen. ${ }^{109}$ Die Alterspensionen der zivilen Staatsbediensteten der RF werden vielmehr gemäß Art. 25 PVG bei Erhöhung der Bezüge der aktiven Staatsbediensteten entsprechend angepasst. 110

Die Anpassung der Arbeitsrenten ,normaler Arbeitnehmer“ erfolgt nach dem ARG hingegen wie folgt:

105 Vgl. Fußn. 32.

106 Vgl. Fußn. 95.

107 Hintergrund dieser gemäß Art. 4 Teil 3 des Gesetzes mit Wirkung vom 1. Januar 2008 in Kraft getretenen Regelung ist im Hinblick auf die Entscheidung Nr. 187-O des VerfG RF vom 11. Mai 2006 („Naumchik“) die Notwendigkeit, eine Gleichbehandlung mit den Vorschriften über die Pensionen von Militärangehörigen herzustellen. Durch Art. 26 Punkt 14 Föderationsgesetz Nr. 213/2009 (Fußn. 74) erweitert ab 1. Januar 2010 die in Art. 14 Punkt 3 PVG vorgesehenen Ausnahmen von der Anrechnung der Arbeitsrente auf die Pension: Die „feste Basishöhe des Versicherungsteils“ wird u.a. insoweit nicht abgezogen, als es sich um Erhöhungen des Basisteils wegen Erreichen des 80ten Lebensjahrs oder wegen Fürsorge für ein arbeitsunfähiges Familienmitglied handelt (vgl. hierzu II.1.a und Fußn. 83).

108 Zum Stand 1. Juli 2007 erhielten 33.127 zivile Staatsbedienstete der RF eine Alterspension nach dem PVG in einer Höhe von insgesamt (einschließlich des Anteils der Altersrente) durchschnittlich 4.853 Rubel im Monat, vgl. Kozbanenko, Kommentariy k Zakonu „O gosudarstvennoy grazhdanskoy sluzhbe Rossiyskoy Federatsii““(Fußn. 92), Art. 14.

109 Kozbanenko, a.a.O.

110 Einzelheiten der Indexierung regelt die Verordnung Nr. 346 der Regierung der RF vom 31. Mai 2005 (SZRF Nr. 23 Art. 2276); zuletzt geändert durch Verordnung Nr. 763 vom 14. Dezember 2006 (SZRF Nr. 51 Art. 5466). 
Der Basisteil der Arbeitsrenten wird gemäß Art. 17 Punkt 6 ARG - im Rahmen der hierfür für das entsprechende Haushaltsjahr vorgesehenen Mittel - entsprechend der Inflationsrate angepasst. Der genaue Indexierungskoeffizient wird durch Verordnung der Regierung der RF festgelegt. Auf Grund des im ARG vorgesehenen Haushaltsvorbehalts lagen die Anpassungen der Basisrenten in der Praxis bislang häufig unterhalb der Inflationsrate. ${ }^{111}$ Nur der Versicherungsteil der Arbeitsrenten orientiert sich gemäß Art. 17 Punkt 7 ARG an der Lohnentwicklung der erwerbstätigen Bevölkerung, allerdings in einem komplexen Verfahren, das auch die Entwicklung des Preisniveaus berücksichtigt und ebenfalls Spielraum für geringere Anhebungen läßt:

- Bei Anstieg des Preisniveaus innerhalb eines laufenden Kalendervierteljahrs um nicht weniger als $6 \%$ erfolgt jeweils für das folgende Kalendervierteljahr einen Monat vorab, d.h. zum 1. Februar, 1. Mai, 1. August und zum 1. November, eine Rentenanpassung.

- Bei Sinken des Preisniveaus innerhalb eines laufenden Kalendervierteljahrs um nicht weniger als $6 \%$ erfolgt jeweils für das folgende Kalenderhalbjahr, d.h. zum 1. August und zum 1. Februar eine Rentenanpassung, es sei denn innerhalb des entsprechenden Kalenderhalbjahres erfolgt eine Anpassung wegen Preisanstiegs.

- Falls innerhalb eines laufenden Kalenderhalbjahres ein Preisanstieg von weniger als $6 \%$ vorliegt, werden die Renten ebenfalls angepasst, es sei denn, daß innerhalb des letzten Jahres Anpassungen nach den ersten beiden Alternativen erfolgten.

- Die vorgenannten, am Preisniveau orientierten Rentenanpassungen haben jedoch nur vorläufigen Charakter. ${ }^{112}$ Gemäß Art. 17 Punkt 7 Unterpunkt 5 ARG erfolgt am Ende des Kalenderjahres die Berechnung des Wachstums des durchschnittlichen Monatsgehalts in der RF. Zum 1. April des folgenden Jahres erfolgt dann orientiert an dieser Berechnung eine ergänzende Erhöhung des Versicherungsanteils der Arbeitsrenten.

Der kapitalgedeckte Anteil der Arbeitsrente unterliegt gemäß Art. 17 Punkt 9 ARG ebenfalls einer jährlichen Anpassung, jeweils zum 1. Juli und erstmals in dem Jahr, das auf die erstmalige Berechnung und Festlegung der Höhe des kapitalgedeckten Anteils folgt. Die Anpassungen erfolgen unter Berücksichtigung der Wertentwicklung des kapitalgedeckten Anteils und ggf. unter Berücksichtigung von Veränderungen der zu erwartenden Bezugszeit, die der erstmaligen Berechnung und Festlegung der Höhe des kapitalgedeckten Anteils zu Grunde gelegt wurde. ${ }^{113}$

111 Tuchkova/Zakharov, Pensionnaya reforma v Rossii (Die Pensionsreform in Russland), 2002, S. 33.

112 Zurabov, Kommentariy k pensionnomu zakonodatel'stvu Rossiyskoy Federatsii (Fußn. 85), S. 596. Die Auszahlung der Pensionen erfolgt allerdings durch den Rentenversicherungsfonds, der insoweit Transfers aus dem Staatshaushalt erhält, vgl. Art. 6 PVG idF des Föderationsgesetzes Nr. 213/2009 (Fußn. 74).

113 Tuchkova/Zakharov, Pensionnaya reforma v Rossii (Fußn. 111), S. 34. 


\section{Finanzierung der Alterssicherung der Staatsbediensteten}

Die Finanzierung sämtlicher Pensionen und Versorgungsleistungen nach dem PVG erfolgt aus dem Haushalt der RF, aus Mitteln des allgemeinen Steueraufkommens oder anderer allgemeiner staatlicher Einnahmequellen. Anders als für die allgemeinen Arbeitsrenten müssen daher keine Beiträge bzw. keine Sozialsteuer gezahlt werden. ${ }^{114}$

\section{Auswertung}

Die Dienstverhältnisse der zivilen Staatsbediensteten der RF haben sowohl öffentlich-rechtlichen als auch privatrechtlichen (arbeitsrechtlichen) Charakter. Die Entstehung eines Dienstverhältnisses erfolgt durch einen öffentlich-rechtlichen Ernennungsakt und den Abschluss des „Dienstkontrakts“, der kein gewöhnlicher Arbeitsvertrag ist. Das Arbeitsrecht wird durch spezifische dienstrechtliche Regelungen des ZDG überlagert. Das ZDG findet auf alle zivilen Staatsbediensteten Anwendung, unabhängig davon, ob sie hoheitliche Aufgaben wahrnehmen oder nicht. Seine Regelungen verleihen den Staatsbediensteten einen besonderen Status, der insbesondere durch umfassende Kataloge von Rechten und Pflichten sowie durch Beschränkungen und Verbote gekennzeichnet ist. Ein öffentlich-rechtliches Treueverhältnis ist jedoch nicht geregelt. Wesentlicher Unterschied zu den hergebrachten Grundsätzen i.S.d. Art. 33 Abs. 5 GG ist zudem das Fehlen des Lebenszeitprinzips. Zivilen Staatsbediensteten und Kommunalbediensteten sowie ihren Familien wird durch das ZDG und das KDG sozialer Schutz bei Krankheit und im Alter (bzw. als Hinterbliebene) „nach den Föderationsgesetzen“ garantiert. Diese Garantien sind allerdings verfassungsrechtlich nicht stärker abgesichert als der soziale Schutz aller Beschäftigten. ${ }^{115}$ Ein Alimentationsprinzip zugunsten von Staatsbediensteten kennt die Verf RF nicht.

In der Literatur wird teilweise aus der Verf RF abgeleitet, daß der Gesetzgeber bei der Ausgestaltung der Altersversorgung von Staatsbediensteten das Prinzip der Einheitlichkeit des Staatsdienstes zu beachten hat. Zwar hat dieses einfachgesetzlich geregelte Prinzip 116 im Hinblick auf Art. 5 Teil 3 Verf RF, wonach sich der Föderalismus der RF auf die Einheit des Systems der Staatsgewalt gründet, einen verfassungsrechtlichen Hintergrund. ${ }^{117}$ Richtigerweise beziehen sich die Vorgaben des Art. 5 Teil 3 Verf RF aber

114 Zurabov, Kommentariy k pensionnomu zakonodatel'stvu Rossiyskoy Federatsii (Fußn. 85), S. 57.

115 Vgl. das Grundrecht auf soziale Sicherheit gemäß Art. 39 Verf RF.

116 Art. 3 Teil 1 Abs. 5 SDSG, Art. 4 Punkt 2 ZDG.

117 Obolonskiy, Gosudarstvennaya sluzhba: kompleksnyy podkhod (Fußn. 10), S. 72. Als Grundlage der Einheit des Systems der Staatsgewalt wird in der Literatur zudem teilweise Art. 3 Teil 1 Verf $\mathrm{RF}$ angeführt, wonach alleinige Quelle der Staatsgewalt das multinationale Volk der RF ist und hieraus das Erfordernis einer gleichförmigen Regulierung von Grundlagen des Staatsdienstes aller 
nur auf die Staatsorganisation und können daher nicht so weit ausgelegt werden, daß eine einheitliche Absicherung aller Arten von Staatsbediensteten vorzusehen ist. Darüber hinausgehende Inhalte des Prinzips der Einheitlichkeit des Staatsdienstes sind nur einfachgesetzlich geregelt (vgl. für die Absicherung im Alter Art. 54 Teil 3 ZDG ${ }^{118}$ ) und binden daher den Gesetzgeber nicht. Derzeit ist das Prinzip der Einheitlichkeit des Staatsdienstes im Bereich der Pensionsversorgung nicht realisiert. Die Pensionsversorgung ziviler Staatsbediensteter unterscheidet sich deutlich von der Pensionsversorgung Militärangehöriger und Angehöriger der Rechtsschutzorgane. 119

Teil der 2002 in Kraft getretenen Rentenreform war auch die Neuregelung der Altersversorgung der Staatsbediensteten durch das PVG. Durch die Reform wurde das bis dahin gewachsene System, nach dem zivile Staatsbedienstete auf Grund von Präsidialerlassen Zuschläge zu gewöhnlichen Arbeitsrenten erhalten, im Grundsatz beibehalten, jedoch auf eine gesetzliche Grundlage gestellt. Anstelle von Zuschlägen wurde eine Alterspension eingeführt, auf die die normale Arbeitsrente der zivilen Staatsbediensteten angerechnet wird. Da die Pensionen der zivilen Staatsbediensteten nach dem PVG deren Arbeitsrenten nach dem ARG gemäß Art. 14 Teil 1 PVG auf ein festes Versorgungsniveau hin aufstocken, wirken sich Erhöhungen (und ggf. ein Absinken) der Arbeitsrenten auf das Versorgungsniveau der Staatsbediensteten nicht aus. Da allerdings nur der Basisteil und der Versicherungsteil der Arbeitsrenten gemäß Art. 14 Teil 1 PVG auf die Pensionen der Staatsbediensteten angerechnet werden, wirkt sich die Einführung des kapitalgedeckten Elements der Arbeitsrente durch die Rentenreform des Jahres 2002 künftig (kapitalgedeckte Rentenanteile sind nur für Versicherten ab dem Geburtsjahrgang 1967 vorgesehen) auch auf das Versorgungsniveau der Staatsbediensteten positiv aus. Das Rentenniveau der allgemeinen Arbeitsrenten nach dem ARG liegt unter dem Versorgungsniveau, das Staatsbedienstete nach dem PVG erhalten. Die Berechnungsgrundlagen für die Altersvorsorge und die jährlichen Anpassungen sind für Staatsbedienstete günstiger als für normale Arbeitnehmer. Denn die Höhe der Arbeitsrente hängt von der Höhe des in den jeweiligen Arbeitsjahren erzielten Einkommens ab. Die Höhe der Pensionen der Staatsbediensteten richtet sich hingegen nach dem Einkommen des letzten Jahres der Diensttätigkeit. ${ }^{120}$ Auch hinsichtlich der Anpassungen des Versorgungsniveaus sind die Staatsbediensteten besser als normale Arbeitnehmer gestellt, da sich die Anpassungen für Staatsbedienstete gemäß Art. 25 Abs. 1 PVG an den jeweiligen Gehaltserhöhungen im Staatsdienst orientieren, während zumindest der Basisanteil der Arbeitsrente gemäß Art. 17 Punkt 6 ARG nur eine Inflationsanpassung erfährt. Nur

staatlichen Ebenen abgeleitet, vgl. Fritzsche, Der zivile Staatsdienst in der Russischen Föderation (Fußn. 11), S. 226.

118 In Art. 54 Teil 3 ZDG wird auf ein Föderationsgesetz „Über die staatliche Pensionsversorgung für Bürger im Staatsdienst und ihre Familien“" verwiesen, das für alle Arten von Staatsbediensteten gelten soll. Ein solches Gesetz wurde allerdings bisher nicht verabschiedet.

119 Vgl. zu den Militärangehörigen Fußn. 91.

120 Savost'yanova, in: Gusov, Pravo sotsial'nogo obespecheniya Rossii (Fußn. 70), S. 276. 
die Anpassung des Versicherungsanteils der Arbeitsrenten ist an der Einkommensentwicklung der Arbeitnehmer orientiert. Diese Unterschiede zwischen der Pensionsversorgung der Staatsbediensteten und den Arbeitsrenten ,normaler“ Arbeitnehmer werden dadurch verstärkt, daß das Arbeitsrentenniveau oft nicht ausreicht, um das Existenzminimum im Alter zu sichern. Im Hinblick darauf, daß das VerfG RF die fehlende Absicherung des Existenzminimums im Alter beanstandet hat ${ }^{121}$, erfolgten in den vergangenen Jahren deutliche Anhebungen des Basisanteils der Arbeitsrenten. Die durchschnittliche Gesamtrentenhöhe betrug im Jahr 20062.726 Rubel ${ }^{122}$ monatlich (demgegenüber betrug das durchschnittliche Pensionsniveau der Staatsbediensteten im Jahr 20074.853 Rubel im Monat ${ }^{123}$ ).

Durch jüngste gesetzliche Änderungen im Jahr 2009 wurde das Arbeitsrentenniveau nochmals erheblich gesteigert. Insbesondere wurde der Basisanteil der Arbeitsrenten ab 1. Dezember 2009 auf 2.562 Rubel (5.124 Rubel ab dem 80ten Lebensjahr) angehoben. ${ }^{124}$ Durch das Änderungsgesetz Nr. 213 vom 24. Juli 2009 wurde im Sozialhilfegesetz RF 125 vorgesehen, daß Rentner, deren Rente das gesetzlich festgelegte Existenzminimum nicht erreicht (Ende 20083.712 Rubel) ${ }^{126}$, einen "Zuschlag“ erhalten, damit sie das gesetzlich festgelegte Existenzminimum erreichen. Weiter wurde durch dieses Änderungsgesetz für Rentner, die für die Jahre bis 2001 eine Arbeitszeit (,trudovoj staž“"127) nach dem bis dahin geltenden Rentensystem vorweisen können, eine höhere „Bewertung“ des für diese Jahre gutgeschrieben Rentenkapitals mit Wirkung ab dem Jahr 2010 eingeführt: Die nach der Rentenformel für die Jahre bis 2001 anzusetzende Summe wird pauschal um 10 \% zuzüglich ein Prozent für jedes Jahr Arbeitszeit in der Zeit vor 1991 erhöht. 128

121 Entscheidung Nr. 17-O des VerfG RF vom 15. Februar 2005 („Enborisova“).

122 Vgl. Statistik „Grundlegende Daten der Pensionsversorgung“ des Föderalen Staatsamts für Statistik (unter: http://www.gks.ru/bgd/regl/b07_13/IssWWW.exe/Stg/d02/06-11.htm).

123 Kozbanenko, Kommentariy k Zakonu „O gosudarstvennoy grazhdanskoy sluzhbe Rossiyskoy Federatsii“ (Fußn. 92), Art. 14.

124 Vgl. ARG idF des Föderationsgesetzes Nr. 72 vom 28. April 2009 (SZRF Nr. 18 Art. 2152).

125 Föderationsgesetz Nr. 178 vom 17. Juli 1999 „Über die staatliche Sozialhilfe“ (SZRF Nr. 29 Art. 3699) idF des Föderationsgesetzes Nr. 213/2009 (Fußn. 74).

126 Gemäß der Verordnung der Regierung der RF Nr. 418 „Über die Festlegung der Höhe des Existenzminimums in der RF für das vierte Quartal 2008“ (SZRF Nr. 21 Art. 2567) betrug das Existenzminimum Ende 2008 für Rentner 3.712 Rubel (für arbeitsfähige Personen 5.086 Rubel, für Kinder 4.472 Rubel).

127 Der Begriff ,trudovoj staž“ stand im russischen Rentensystem vor Inkrafttreten des Arbeitsrentengesetzes im Jahr 2002 für die Gesamtsumme der Arbeitstätigkeit und anderer gesellschaftlich nützlichen Tätigkeiten, wobei Tätigkeiten unabhängig davon erfasst sind, wo und wie sie erbracht wurden und ob sie bezahlt oder unbezahlt, unterbrochen oder ununterbrochen erbracht wurden. Auch einige andere Zeiträume können nach Maßgabe der Gesetzgebung auf die „trudovoj staž“ angerechnet werden. Vgl. zur Definition Kobzeva, in: Gusov, Pravo sotsial'nogo obespecheniya Rossii (Fußn. 70), S. 191.

128 Vgl. Art. 30.1 ARG idF des Föderationsgesetzes Nr. 213/2009 (Fußn. 74). 
Es bleibt abzuwarten, ob sich durch die jüngsten Erhöhungen der Arbeitsrenten der Abstand zum Versorgungsniveau der zivilen Staatsbediensteten verringern wird. Allerdings sind durch das Föderationsgesetz Nr. 187 vom 18. Juli 2009 parallel bereits Erhöhungen der Pensionen der Staatsbediensteten verabschiedet worden. 129

129 Vgl. oben II. 3: Erhöhung der Obergrenze für das nach Art. 21 zu berücksichtigende Durchschnittsgehalt des zivilen Staatsbediensteten auf das 2,8-fache des Grundgehalts. 


\section{Schweiz ohne Beamte - Staatsdiener ohne Pension? Zur Alterssicherung des eidgenössischen Bundespersonals}

Friso Ross

I. Grundlegung

1. Bundespersonal als Vergleichsgruppe

2. Rechtliche Stellung des Bundespersonals

3. Alterssicherung des Bundespersonals im Kontext allgemeiner sozialer Sicherung

II. Ausgestaltung der Alterssicherung des Bundespersonals

1. Das Drei-Säulen-Konzept der Alterssicherung

2. Die AHV als Erste Säule und Basissicherung

a) Leistungen der AHV: Minimal- und Maximalrente

b) Finanzierung der AHV

3. Berufliche Vorsorge als Zweite Säule

a) Einrichtungen der Beruflichen Vorsorge des Bundespersonals

b) Leistungen der Beruflichen Vorsorge: Kapitalgedeckte Altersrente

c) Leistungen der Beruflichen Vorsorge: Kapitalabfindung

d) Finanzierung der Beruflichen Vorsorge für das Bundespersonal

e) Sicherung der Beruflichen Vorsorge für das Bundespersonal

III. Bewertung 